NBER WORKING PAPER SERIES

\title{
A NEW METHOD TO ESTIMATE RISK AND RETURN OF NON-TRADED ASSETS FROM CASH FLOWS: THE CASE OF PRIVATE EQUITY FUNDS
}

\author{
Joost Driessen \\ Tse-Chun Lin \\ Ludovic Phalippou \\ Working Paper 14144 \\ http://www.nber.org/papers/w14144
NATIONAL BUREAU OF ECONOMIC RESEARCH
1050 Massachusetts Avenue
Cambridge, MA 02138
June 2008

We thank Michael Brennan, Gurdip Bakshi, Magnus Dahlquist (AFA discussant), Frank de Jong, Thomas Dangl, Steve Kaplan, Rainer Lauterbach (EFA discussant), André Lucas, Tarun Ramadorai (SIFR discussant), Lubos Pástor, Per Stromberg, Marno Verbeek, Annette Vissing-Jorgensen (NBER discussant), Bas Werker, and seminar participants at Bergen, BI Oslo, HEC Paris, Tilburg, SIFR private equity conference, NBER meetings on private equity, the Vienna Symposia on Asset Management, the Rotterdam Conference on Asset Management, the EFA 2007 in Ljubljana, the NTU IEFA conference, the ECB-CFS conference, and Netspar Pension Workshop for valuable comments. We thank Inquire-UK for financial support. Views are those of authors and not that of Inquire-UK. All authors are affiliated to the University of Amsterdam Business School, Roetersstraat 11, 1018 WB Amsterdam, the Netherlands. Emails: J.J.A.G.Driessen@uva.nl, T.C.Lin@uva.nl and L.Phalippou@uva.nl. The views expressed herein are those of the author(s) and do not necessarily reflect the views of the National Bureau of Economic Research.

NBER working papers are circulated for discussion and comment purposes. They have not been peerreviewed or been subject to the review by the NBER Board of Directors that accompanies official NBER publications.

(C) 2008 by Joost Driessen, Tse-Chun Lin, and Ludovic Phalippou. All rights reserved. Short sections of text, not to exceed two paragraphs, may be quoted without explicit permission provided that full credit, including $\left({ }^{\circ}\right.$ notice, is given to the source. 
A New Method to Estimate Risk and Return of Non-Traded Assets from Cash Flows: The Case of Private Equity Funds

Joost Driessen, Tse-Chun Lin, and Ludovic Phalippou

NBER Working Paper No. 14144

June 2008

JEL No. G12,G23

\begin{abstract}
We develop a new GMM-style methodology with good small-sample properties to assess the abnormal performance and risk exposure of a non-traded asset from a cross-section of cash flow data. We apply this method to a sample of 958 mature private equity funds spanning 24 years. Our methodology uses actual cash flow data and not intermediary self-reported Net Asset Values. In addition, it does not require a distributional assumption for returns. For venture capital funds, we find a high market beta and significant under-performance. For buyout funds, we find a low beta and no abnormal performance, but the sample is small. Larger funds have higher returns due to higher risk exposures and not higher alphas. We also find that Net Asset Values significantly overstate fund market values for the subset of mature and inactive funds.
\end{abstract}

Joost Driessen

University of Amsterdam

j.j.a.g.driessen@uva.nl

Tse-Chun Lin

University of Amsterdam

T.C.Lin@uva.nl
Ludovic Phalippou

University of Amsterdam

L.Phalippou@uva.nl 


\title{
A new method to estimate risk and return of non-traded assets from cash flows: The case of private equity funds*
}

\author{
Joost Driessen \\ Tse-Chun Lin \\ Ludovic Phalippou
}

June 2008

\begin{abstract}
We develop a new GMM-style methodology with good small-sample properties to assess the abnormal performance and risk exposure of a non-traded asset from a crosssection of cash flow data. We apply this method to a sample of 958 mature private equity funds spanning 24 years. Our methodology uses actual cash flow data and not intermediary self-reported Net Asset Values. In addition, it does not require a distributional assumption for returns. For venture capital funds, we find a high market beta and significant under-performance. For buyout funds, we find a low beta and no abnormal performance, but the sample is small. Larger funds have higher returns due to higher risk exposures and not higher alphas. We also find that Net Asset Values significantly overstate fund market values for the subset of mature and inactive funds.
\end{abstract}

${ }^{*}$ We thank Michael Brennan, Gurdip Bakshi, Magnus Dahlquist (AFA discussant), Frank de Jong, Thomas Dangl, Steve Kaplan, Rainer Lauterbach (EFA discussant), André Lucas, Tarun Ramadorai (SIFR discussant), Lubos Pástor, Per Stromberg, Marno Verbeek, Annette Vissing-Jorgensen (NBER discussant), Bas Werker, and seminar participants at Bergen, BI Oslo, HEC Paris, Tilburg, SIFR private equity conference, NBER meetings on private equity, the Vienna Symposia on Asset Management, the Rotterdam Conference on Asset Managment, the EFA 2007 in Ljubljana, the NTU IEFA conference, the ECB-CFS conference, and Netspar's Pension Workshop for valuable comments. We thank Inquire-UK for financial support. Views are those of authors and not that of Inquire-UK. All authors are affiliated to the University of Amsterdam Business School, Roetersstraat 11, 1018 WB Amsterdam, the Netherlands. Emails: J.J.A.G.Driessen@uva.nl, T.C.Lin@uva.nl and L.Phalippou@uva.nl. 


\section{A new method to estimate risk and return of non-traded assets from cash flows: The case of private equity funds}

We develop a new GMM-style methodology with good small-sample properties to assess the abnormal performance and risk exposure of a non-traded asset from a cross-section of cash flow data. We apply this method to a sample of 958 mature private equity funds spanning 24 years. Our methodology uses actual cash flow data and not intermediary selfreported Net Asset Values. In addition, it does not require a distributional assumption for returns. For venture capital funds, we find a high market beta and significant under-

performance. For buyout funds, we find a low beta and no abnormal performance, but the sample is small. Larger funds have higher returns due to higher risk exposures and not higher alphas. We also find that Net Asset Values significantly overstate fund market values for the subset of mature and inactive funds.

JEL classification: C51; G12; G23

Keywords: Risk; Abnormal return; Private equity 


\section{Introduction}

The estimation of risk exposure (beta) and abnormal performance (alpha) is at the heart of financial economics. Since Jensen's (1968) time-series regression approach to determine the alpha and beta of a mutual fund, a large literature has been dedicated to refining measures of risk and return (see Cochrane, 2005a, for an overview). However, a commonly encountered situation has received little attention. It is that of a non-traded asset for which we only observe cash flows. For example, private equity fund investors give away cash at different points in time and receive dividends at other points in time during the 10 years of the life of the fund. In this paper, we propose a methodology to measure risk and abnormal return in such a context and apply it to a sample of private equity funds.

The intuition is simple. When the fund is terminated, we know that the market value at that date is zero. This gives a moment condition stating that the expected discounted value of all investments should equal the expected discounted value of all dividends paid out, where the discounting is done using the chosen asset pricing model. Effectively, our method searches for parameter values (alpha and beta) that bring the net present values of cash flows as close to zero as possible. If we have a sufficient number of moment conditions (i.e., funds), the system is overidentified and we can find the parameters of the asset pricing model that best fit the observed cross-section of cash flows using Generalized Method of Moments estimation (GMM). One can see this setup as a search for a mimicking fund that best fits the cash flows of the private equity funds, where the mimicking portfolio is a stock index fund. This fund can be levered by the investor (hence reaching any beta level) and fund fees should be paid (fees would be negative for a positive alpha and vice versa).

We show that our method generates consistent estimates of risk and abnormal returns

without assuming a distribution for returns. Avoiding this distributional assumption is important because i) it is difficult to estimate the probability density function since market prices are not observable and ii) in asset classes such as venture capital or buyout, the return distribution is nonstandard with a cluster at $-100 \%$ and fat right tail. We also show that our estimator remains consistent when the cash flow timing is endogenous.

We study the small-sample properties of our estimator in order to minimize small 
sample biases. We show that the bias is reduced when each moment condition corresponds to a portfolio of funds instead of a single fund. We also find that it is important to form portfolios based on fund inception year. Grouping funds reduces idiosyncratic risk, which is a key element in the precision of the abnormal return estimate. Moreover, grouping on the basis of inception year enables a better identification of beta because portfolios with different inception years are subject to different market returns. Basically, the cross-section of inception-year portfolios provides information on beta while alpha is identified from the restriction that the final value of liquidated funds equals zero. Finally, we show that a log-transformation of the moment condition further improves small sample properties.

We illustrate these findings with a Monte Carlo simulation. We calibrate an economy following the setup and parameter estimates of Cochrane (2005b). The simulation confirms that our estimator has a negligible bias in a small sample (less than ten basis point per year for alpha and less than 0.01 for beta).

We apply our new methodology to a trillion-dollar asset class: private equity funds. These funds are financial intermediaries that are typically classified as venture capital focused or buyout focused. They are not publicly traded and investors observe only a stream of cash flows for about 10 years. Hence standard estimation techniques cannot be applied.

Our dataset consists of 958 private equity funds with over 25,000 cash flow observations between 1980 and 2003. We include all funds that are more than 10 years old (the typical fund duration). For funds that are not reported as liquidated, we predict the final market value using an econometric model. This model relates the realized market value of subsequently liquidated funds to a set of fund characteristics.

We find that venture capital funds have a significantly different risk profile than buyout funds. Venture capital funds have a market beta of 3.21, while buyout funds have a market beta of 0.33 . In line with these estimates, we observe that many venture capital funds paid large dividends mainly in the late 1990s, precisely when the stock market had previously experienced large returns. In 2001-2003, when stock markets experienced lower returns, dividends from venture capital funds have been rare. Such a pattern is consistent with a high beta for venture capital. For buyout funds, we do not observe a strong dependence on 
market returns. The dividends of buyout funds have been remarkably steady throughout our time period. We discuss in the text potential explanations for such a result, with the caveat that the buyout sample is much smaller than the venture capital sample.

For venture capital, we find a large significant negative CAPM alpha of $-15 \%$ per year and a Fama-French alpha of $-8 \%$. These results complement the results on the "private equity premium puzzle" for entrepreneurial investments as documented by Moskowitz and Vissing-Jorgensen (2002). For buyout funds, the alpha is slightly positive but insignificant.

Our econometric model for final market values predicts that the value of non-liquidated funds beyond the typical liquidation age (10 years) is only $30 \%$ of the self-reported Net Asset Value. In contrast, for funds that are liquidated, market values are close to Net Asset Value. This substantial discrepancy comes from the fact that the non-liquidated funds have not distributed dividends for a long time (more than 3 years) and have not updated their Net Asset Value for a long time (more than 2 years); two characteristics that are significantly associated with poorer subsequent cash flows according to our econometric model.

In sum, we show that observing the time series of market values is not necessary to consistently estimate risk and return. Neither are distributional assumptions on returns. A cross-section of cash flow streams is sufficient but it comes at the cost of assuming a common parametric structure for the cross-section of alphas and betas. For example, we first allow alpha and beta to be a function of focus (venture capital, buyout). Subsequently, we make the alpha and beta a function of both fund size and focus, thereby having a different alpha and beta for each fund. This specification allows us to shed light on the finding that large funds have a higher total return than small funds (Kaplan and Schoar, 2005, and Phalippou and Gottschalg, 2007). We find that alpha is not related to size but beta is significantly and positively related to size. The higher return of large funds is thus due to higher risk exposure and not higher abnormal performance.

We also conduct a large number of robustness tests. We observe that results remain essentially unchanged for venture capital funds, while the results for buyout funds are somewhat less stable. Still, across all specifications and setups, buyout funds have low betas and abnormal performance close to zero. The robustness results also confirm that our 
estimator has good small-sample properties.

The rest of the paper proceeds as follows. In Section 2, we discuss related literature. Section 3 contains a description of the GMM approach and presents a simulation study to assess the small-sample properties. Section 4 describes the private equity industry, our data, and the model for final market values. Section 5 presents the empirical results and robustness checks. Section 6 concludes.

\section{Related Literature}

Our work is related to that of Cochrane (2005b) and Korteweg and Sorensen (2008) who assess the alpha and beta of US venture capital projects gross-of-fees (e.g. the return on Google from the first observed round of venture financing until the IPO date). Their data have two important characteristics. First, returns are observed mainly for investments that perform well (e.g., those going public). Second, information may be missing for intermediary rounds. ${ }^{1}$ Cochrane $(2005 \mathrm{~b})$ tackles both issues with a maximum likelihood approach and Korteweg and Sorensen (2008) tackles the first issue with a Bayesian methodology and the second one by removing all observations for which a return cannot be computed. Both papers need to estimate a selection equation to correct for the selection bias and thus need to assume a parametric distribution for returns.

We view the approach of Cochrane-Korteweg-Sorensen (CKS) and our approach as complementary. Using individual investment data (i) may lead to more precise estimates of risk and return since more information is used and (ii) allows for an analysis of risk and return as a function of project characteristics. This comes at the cost of assuming a parametric structure for both the project return distribution and the selection equation. In contrast, our approach does not require a parametric assumption on the return distribution. In addition, given that our methodology only needs fund-level data it does not suffer from

\footnotetext{
${ }^{1}$ Venture Capital (VC) funds invest in distinct projects in so-called rounds. A return from round $n$ to $n+1$ is observed only if i) project valuation post-money at round $n$ is observed, ii) there is a subsequent valuation round $n+1$ which happens only if investments do well enough, and iii) project valuation pre-money at round $n+1$ is observed. Cochrane $(2005 \mathrm{~b})$ reports that a return could not be computed in $58 \%$ of the cases and a subsequent round (item 2) is not observed in $23 \%$ of the cases. Korteweg and Sorensen (2008) use an improved sample and cannot compute a return in $36 \%$ of the cases.
} 
a project selection bias since the fund-level cash flows include all investments (both good and bad). ${ }^{2}$ These are the core differences in terms of methodology.

In terms of the empirical estimates of risk and return we provide, it is important to note that we do not exactly measure the same object. CKS measure risk and return of the venture capital project when it is under the control of the venture capital firm. For example, in case of an IPO-exited project, the return observed by CKS will be based on the IPO offering price. In contrast, our data give the timing and amount of dividends received by investors, which in case of an IPO are typically based on the stock price after the lockup period. ${ }^{3}$ A second difference between project returns and investor returns comes from fees. As fees vary across funds, over time, and are non-linear in performance, they affect estimates of both risk and abnormal return. Hence, the gross-of-fees risk-return estimates of CKS differ from the net-of-fees risk-return that we measure here. A third reason why project returns and investor returns differ is that the stake of fund managers in a project changes over the project's life. If the stake of a fund manager is higher when the expected return is higher then the investor's performance will be superior to that of the project. Finally, our dataset contains US venture capital funds (as CKS) but also contains cash flows of buyout funds and non-US funds.

In terms of empirical results, the beta for venture capital reported by Korteweg and Sorensen is close to our estimate, while Cochrane's estimate for beta is lower (1.9). The after-fee alpha, however, is significantly negative in our case, while both Cochrane (2005b) and Korteweg and Sorensen (2008) report large positive alphas (30\% and 150\% per annum, respectively). ${ }^{4}$

\footnotetext{
${ }^{2}$ Sample selection issues are relatively low in our dataset as cash flows are reported by investors and for all the investments of a given fund, including bad ones. A small selection bias may nonetheless exist in our dataset (Phalippou and Gottschalg, 2007). Investors that report fund cash flows to Venture Economics appear to have some fund-picking abilities. Moreover, we do have non-liquidated funds in our sample, but we show that their treatment does not affect results much (section 5.3.1).

${ }^{3}$ An extreme example is the eBay IPO. Benchmark Partners return in eBay was 20 times the investment at the IPO. This is what CKS would observe. However, investors received the eBay stocks 6 months after the IPO, when the price had increased by more than 3000\% making their stake worth 700 times the investment. This is the dividend we would observe in our data.

${ }^{4}$ The difference between these estimates for alpha and ours is larger than what can be justified by fees. Our results are consistent with what Kaplan and Schoar (2005) find. The discrepancy could be due to data errors but it is unfortunately not possible to compare the two datasets to study differences. Another possible reason for the discrepancy is that the correction for sample selection by CKS is not sufficient.
} 
Our paper is also related to Kaplan and Schoar (2005) and Phalippou and Gottschalg (2007) who benchmark private equity fund performance to that of the S\&P 500 index, effectively assuming a CAPM with beta equal to one. Our results suggest that the natural benchmark for venture capital is much higher. According to the CAPM and using average past risk-free rates and S\&P 500 returns, our estimates imply a required return above $20 \%$ per year (instead of $13 \%$ per year with a beta equal to one). In addition, our results suggest that most of the Net Asset Values (NAVs) reported by mature funds (beyond their 10th anniversary) are too high, especially for inactive funds. We thus offer an econometric estimate of the fund market value that lies in between the Kaplan-Schoar assumption that all final NAVs reflect market value and the Phalippou-Gottschalg assumption that the final NAVs of mature funds are worthless.

Finally, our paper is related to that of Jones and Rhodes-Kropf (2004). They derive a theoretical model showing that idiosyncratic risk should be priced in private equity. To test it, they estimate the risk faced by private equity fund investors. They assume that the quarterly self-reported NAVs are stale but unbiased estimates of market values and proxy log returns by arithmetic returns. They obtain alpha and betas by regressing NAV-based returns on both contemporaneous and lagged risk factors. ${ }^{5}$ In this paper, we show that NAVs reported by mature funds are systematically biased. That is why we do not take NAVs as market values in this paper.

\section{A New Approach to Estimate Risk and Abnormal Return}

We propose a GMM-style methodology to estimate risk and return of a non-traded asset for which we only observe cash flows. In this section, we first provide an intuition for our approach. We then illustrate its working with a simple example. This example is then used to show the assumptions we make and the assumptions we do not make. Next, in section 3.2, we show that a first GMM approach although consistent would generate a small sample bias. Consequently, in section 3.3, we introduce three improved GMM-style

\footnotetext{
${ }^{5}$ The reader may refer to Phalippou (2008) for further discussion of this method and of alternative approaches to risk and return evaluation.
} 
approaches. These approaches preserves statistical consistency while minimizing the small sample biases. Section 3.4 discusses how to best group funds into portfolios and how to calculate standard errors for our new approach. Finally, section 3.5 shows Monte Carlo simulations to illustrate our theoretical claims and select the best approach.

\subsection{The basic idea}

\subsubsection{The intuition: A mimicking fund}

We illustrate our approach with a mimicking fund analogy. We define the mimicking fund as a levered position on the S\&P 500 index. By increasing or decreasing leverage, the investor can reach any level of systematic risk. The question we ask is what is the beta (i.e. leverage) of the mimicking fund that best mimics a private equity fund.

By definition, the mimicking fund should have the same cash flows as the private equity fund. That is, whenever the investor gives money to the private equity fund, the same amount goes into the mimicking fund and whenever money is being paid to the investor, we assume the same amount comes out of that same mimicking fund. When the private equity fund is liquidated, its value is zero by definition. The mimicking fund should thus also have a value of zero. This provides one equation in one unknown. Hence, only knowing the cash flows is enough to estimate systematic risk exposure.

\subsubsection{Example}

We show how our idea works with two private equity funds. In this example, we assume that the risk-free rate is zero and that there are no idiosyncratic shocks. The true model is the CAPM with a beta of 1.5. Both funds invest 100 in 2 projects for 2 years. In a CAPM economy, the final dividend equals $100\left(1+1.5 R_{m, t}\right)\left(1+1.5 R_{m, t+1}\right)$. The cash flows generated in such an economy are shown below. 


\begin{tabular}{|c|c|c|c|}
\hline Year & Market ret. & Fund 1: Cash flows (year end) & Fund 2: Cash flows (year end) \\
\hline 1 & - & -100 & 0 \\
\hline 2 & $20 \%$ & -100 & -100 \\
\hline 3 & $15 \%$ & 159 & -100 \\
\hline 4 & $5 \%$ & 132 & 132 \\
\hline 5 & $-10 \%$ & 0 & 91 \\
\hline 6 & $30 \%$ & 0 & 0 \\
\hline
\end{tabular}

The econometrician does not know the true parameter value and does not know which cash flow corresponds to which project. She only observes cash flow amounts and timing. She computes the value $V_{i, j}$ of the mimicking fund for each fund $i$ at the end of year $j$ and obtains the values shown below

\begin{tabular}{|c|c|l|l|}
\hline Year & Market ret. & Mimicking fund 1: Year-end value & Mimicking fund 2: Year-end value \\
\hline 1 & - & $V_{1,1}=100$ & - \\
\hline 2 & $20 \%$ & $V_{1,2}=V_{1,1}(1+\beta \cdot 0.20)+100$ & $V_{2,2}=100$ \\
\hline 3 & $15 \%$ & $V_{1,3}=V_{1,2}(1+\beta \cdot 0.15)-159$ & $V_{2,3}=V_{2,2}(1+\beta \cdot 0.15)+100$ \\
\hline 4 & $5 \%$ & $V_{1,4}=V_{1,3}(1+\beta \cdot 0.05)-132$ & $V_{2,4}=V_{2,3}(1+\beta \cdot 0.05)-132$ \\
\hline 5 & $-10 \%$ & 0 & $V_{2,5}=V_{2,4}(1+\beta \cdot-0.10)-91$ \\
\hline
\end{tabular}

Given that these funds are liquidated at year 4 and 5, respectively, both mimicking funds should have zero value at the liquidation date, i.e. $V_{1,4}=0$ and $V_{2,5}=0$. Solving this system of equations gives a unique solution at $\beta=1.5$, which is the true value. Note that setting $V_{1,4}=0$ and $V_{2,5}=0$ implies that one sets the compounded value of the investments equal to the compounded value of the dividends, where the compounding is done using the pricing model. Equivalently, one can equalize the discounted values.

\subsubsection{Identification}

An important point is that of identification. Each equation above being a third-order polynomial, it may have multiple real solutions. In the above example, multiple real solutions 
exist only if the true beta is below -4 . For instance, if the true beta is -5 , the other solutions are $\beta=-18.8$ and $\beta=-12.8$ for fund 1 and -25.5 and 7.2 for fund 2 . Hence, there is a unique solution to the system of two equations equal to -5 .

Mathematically, the coefficients in the polynomial will depend on the realized market returns so that in general all solutions (except the 'correct' value) will depend on the realized market returns. Hence, as long as the market returns that funds face are different, it seems that there is a unique solution. We do not have a formal proof for uniqueness of the solution but we never find any cases in the examples we took. In addition, we have not found any cases in the Monte Carlo simulations (section 3.5) nor any local minimum in the real data estimation (section 4).

This indicates that it is important to consider funds that are active in different periods (and subject to different market returns) for the identification of beta. This makes intuitive sense. It is by observing cash flow amounts in different market environments that one can learn about systematic risk.

\subsubsection{Assumptions}

Turning to our general framework, there are two key assumptions we make. Our first assumption is a standard assumption in the performance measurement literature.

Assumption 1: The latent return $R_{i j, t}$ on private equity project $j$ of fund $i$ in period $t$ is generated by a linear factor model with idiosyncratic shocks. For example, in case of a CAPM (or one-factor market model) we assume

$$
R_{i j, t}=r_{f, t}+\alpha_{i}+\beta_{i} r_{m, t}+\varepsilon_{i j, t}
$$

where $r_{f, t}$ is the risk-free rate, $r_{m, t}$ is the market return in excess of the risk-free rate, $\varepsilon_{i j, t}$ and $r_{m, t}$ are independent, $\varepsilon_{i j, t}$ and $\varepsilon_{i j, s}$ are independent if $t \neq s$, but with $\varepsilon_{i j, t}$ potentially correlated across projects and $E\left[\varepsilon_{i j, t}\right]=0$. Below we discuss which assumptions we make on these cross-sectional error correlations for the calculation of standard errors.

Assumption 2: Some cross-sectional restrictions are placed on the $\alpha_{i}$ and $\beta_{i}$ parameters. An example of such an assumption is to assume that all funds have the same beta. This 
is what Cochrane (2005b) and Korteweg and Sorensen (2008) assume and what we assume too for the main empirical part. Assumption 2 is necessary in this context because of a lack of a time series of market values. Intuitively, since we observe only a cross-section of funds, we need to impose some cross-sectional restrictions to prevent that we have an underidentified system. Assuming betas to be equal for all funds is, however, just one extreme case of such an assumption. All we need is some restrictions to ensure identification. For example, below, we allow venture capital and buyout funds to have different $\alpha$ and $\beta$. Also, in an extension, we specify that $\beta_{i}=b_{0}+b_{\text {size }} * \ln \left(\right.$ fund_size $\left.e_{i}\right)$. In this case, virtually all funds have a different beta. The pair of parameters $\left(b_{0}, b_{\text {size }}\right)$ however is the same for all funds.

An assumption we do not make is that cash flows are exogenous or that we need to observe some cash flows in each time period. To illustrate this point, assume that cash flows are endogenous in the sense that investments are exited only if the market reaches a certain cumulated performance. For example, it is often argued that investments are exited only after the market went up by more than a certain amount. Let us assume that this amount is $20 \%$. In the table below we show what would be the new cash flow pattern. Solving for beta for this set of cash flows leads to a unique solution which is again $\beta=1.5$, the true systematic risk level. The intuition for this result is that delaying a cash flow by one period simply means that the mimicking portfolio runs for one more period. This has no consequence for the leverage level of the mimicking portfolio that matches our private equity fund cash flows. In our simulation study below, we also allow for endogenous cash flow timing and show in a more realistic setting that we obtain consistent estimates.

\begin{tabular}{|c|c|c|c|}
\hline Year & Market return & Fund 1: Cash flows (year end) & Fund 2: Cash flows (year end) \\
\hline 1 & - & -100 & 0 \\
\hline 2 & $20 \%$ & $130-100=30$ & -100 \\
\hline 3 & $15 \%$ & 0 & -100 \\
\hline 4 & $5 \%$ & 132 & 132 \\
\hline 5 & $-10 \%$ & 0 & 0 \\
\hline 6 & $30 \%$ & 0 & 132 \\
\hline
\end{tabular}




\subsection{The simple GMM approach and its limits}

\subsubsection{Derivation}

We now develop the approach more formally. The underlying idea is as above and we maintain the same two assumptions. The main changes compared to the above example are that we i) allow for a mispricing parameter $\alpha$, ii) introduce an idiosyncratic shock for each private equity project as in equation (1), and iii) allow for a larger cross-section of funds.

The derivations are done with a one-factor market index model (including a constant mispricing parameter $\alpha$ ) for simplicity. A generalization to multi-factor pricing models is trivial as long as the factors are traded assets in order to measure abnormal performance with $\alpha$.

Without loss of generality, we derive the moment conditions for a portfolio of funds (fund-of-funds / FoFs). Each fund-of-funds $i$ invests an amount $T_{i j}$ in project $j$ at date $t_{i j}$. There is a total of $n_{i}$ projects for FoF $i$ (typically, a single private equity fund invests in about 15 projects) and a liquidation dividend $D_{i j}$ is paid at date $d_{i j}$ for each project. The return of a project in each period is the return of the mimicking portfolio plus the realization of an idiosyncratic shock. Hence the dividend of the project at date $d_{i j}$ is given by

$$
D_{i j}=T_{i j} \prod_{t=t_{i j}+1}^{d_{i j}}\left(1+r_{f, t}+\alpha+\beta r_{m, t}+\varepsilon_{i j, t}\right)
$$

If one would observe cash flows at the project level and each project would have only one investment and one dividend, one could estimate $\alpha$ and $\beta$ by simply applying nonlinear regression techniques to equation (2). In practice, however, cash flows are only observed at the fund level and it is not known to which project a given cash flow belongs. This implies that we have to discount or compound all cash flows to a date that is common to all projects in a FoF. Therefore, as we did in the above example, we now multiply equation (2) on both

sides by $\prod_{s=d_{i j}+1}^{L_{i}}\left(1+r_{f, s}+\alpha+\beta r_{m, s}\right)$ where $L_{i}$ is the liquidation date of the last project in the fund-of-funds $i$ 


$$
\begin{aligned}
& D_{i j} \prod_{s=d_{j}+1}^{L_{i}}\left(1+r_{f, s}+\alpha+\beta r_{m, s}\right) \\
& =T_{i j} \prod_{t=t_{i j}+1}^{d_{i j}}\left(1+r_{f, t}+\alpha+\beta r_{m, t}+\varepsilon_{i j, t}\right) \underset{\prod^{\prime} d_{i j}+1}{L_{i}}\left(1+r_{f, s}+\alpha+\beta r_{m, s}\right)
\end{aligned}
$$

Now, we take expectations on both sides of equation (3) with respect to idiosyncratic shocks of all projects in a fund-of-funds. It follows from assumption 1 that idiosyncratic shocks are independent from the factor returns and are not correlated over time. Hence, the expectations of the cross-products of the form $\varepsilon_{i j, t} \varepsilon_{i j, s}$ are equal to zero (as well as higher-order cross-products) for $t \neq s$ and we obtain

$$
E\left[D_{i j} \prod_{s=d_{i j}+1}^{L_{i}}\left(1+r_{f, s}+\alpha+\beta r_{m, s}\right)\right]=E\left[T_{i j} \prod_{t=t_{i j}+1}^{L_{i}}\left(1+r_{f, t}+\alpha+\beta r_{m, t}\right)\right]
$$

This moment condition is the basis of our estimation methodology. Note that we treat the market returns and risk-free rates as exogenous. In other words, we condition upon the realized market returns and risk-free rates when constructing this moment condition.

Next, we use the sample equivalent of the expectations in equation (4) by averaging across projects within a fund-of-funds. The left hand side of (4) for fund-of-funds $i=1, . ., N$ is then estimated by the sample counterpart of the compounded value $(C V)$

$$
\overline{C V}^{D_{i}}(\alpha, \beta)=\frac{1}{n_{i}} \sum_{j=1}^{n_{i}}\left[D_{i j} \prod_{s=d_{i j}+1}^{L_{i}}\left(1+r_{f, s}+\alpha+\beta r_{m, s}\right)\right]
$$

and the right hand side of (4) is estimated by

$$
\overline{C V}^{T_{i}}(\alpha, \beta)=\frac{1}{n_{i}} \sum_{j=1}^{n_{i}}\left[T_{i j} \prod_{t=t_{i j}+1}^{L_{i}}\left(1+r_{f, t}+\alpha+\beta r_{m, t}\right)\right]
$$

As the number of projects per FoF tends to infinity $\left(n_{i} \rightarrow \infty\right)$, the average converges to the expectation asymptotically. The first-step GMM estimator with identity weighting matrix and $N$ fund-of-funds is the solution of the following optimization 


$$
\min _{\alpha, \beta} \sum_{i=1}^{N}\left[\overline{C V}^{D_{i}}(\alpha, \beta)-\overline{C V}^{T_{i}}(\alpha, \beta)\right]^{2}
$$

We have just derived a generalization of what we did in the simple example above. The parameters estimated from this optimization, which is a first-step GMM procedure, are consistent under standard GMM regularity conditions. We label this method the 'Net Compounded Value (NCV) approach'.

Note that our approach differs from the GMM estimation of the pricing kernel based on the Euler equation, which is frequently applied in asset pricing (see Cochrane, 2005a, for an overview) although it is similar in spirit. To illustrate this point, consider the standard CAPM pricing kernel $a+b R_{m, t}$. As shown in Cochrane (2005a, equation 8.3), the parameters $a$ and $b$ can be found by imposing that the risk-free asset and market return are priced correctly. Then, one can write an Euler equation for the cash flows of the fund, and test whether this equation holds or not (at the fund or fund-of-funds level). However, this does not lead to direct estimates of the abnormal performance $\alpha$ or risk loading $\beta$. In principle, the monthly $\alpha$ could be inferred from the pricing error on the Euler equation, but this pricing error is a nonlinear and complicated function of $\alpha$. The $\beta$ is usually estimated in this standard setup by $\operatorname{Cov}\left(R, R_{m}\right) / V\left(R_{m}\right)$. Given that we only observe irregular cash flows for private equity funds, estimating $\beta$ in this way is not possible. In sum, in contrast to the Euler equation approach, our method renders direct estimates of risk exposures and abnormal performance.

\subsubsection{Small-sample bias}

In small samples, the extra compounding we do for most projects introduces a bias. In this subsection, we provide an intuition for this bias using a simplified framework. For the general case, deriving the bias in closed-form proved to be unfeasible and we then rely on a simulation study (section 3.5).

In our simplified framework, we assume that all projects in a fund-of-funds (FoF) have a takedown equal to 1, a duration of one period, and that the risk-free rate is zero. In this case, the average realized dividend of FoF $i$ is 


$$
\frac{1}{n_{i}} \sum_{j=1}^{n_{i}} D_{i j}=\frac{1}{n_{i}} \sum_{j=1}^{n_{i}}\left[T_{i j}\left(1+\alpha+\beta r_{m, t(i)}+\varepsilon_{i j}\right)\right]=\left(1+\alpha+\beta r_{m, t(i)}+\overline{\varepsilon_{i}}\right)
$$

where $\overline{\varepsilon_{i}}=\frac{1}{n_{i}} \sum_{j=1}^{n_{i}} \varepsilon_{i j}$ and where $r_{m, t(i)}$ is the one-period market return that applies to all projects in FoF $i$. Note that asymptotically, as $n_{i}$ tends to infinity, $\overline{\varepsilon_{i}}$ tends to zero $\left(\overline{\varepsilon_{i}} \rightarrow^{P} 0\right)$.

To capture that the GMM-estimator compounds most projects beyond their dividend date, we assume in this simplified setup that the final liquidation date is $t(i)+1$, so that we compound one period beyond the date at which the projects pay out their dividend. This is like the first project done by fund 1 in the example in 3.1.2. This first project lives until date 3 but its value is compounded to date 4 .

Let $\alpha$ and $\beta$ be the true parameter values, and $\widetilde{\alpha}$ and $\widetilde{\beta}$ be the parameters over which we optimize. In the simplified setup, we use equation (8) to write the NCV-based GMM estimation as follows

$$
\begin{aligned}
& \min _{\widetilde{\alpha}, \widetilde{\beta}} \sum_{i=1}^{N}\left[\frac{1}{n_{i}} \sum_{i=1}^{n_{i}} D_{i j}\left(1+\widetilde{\alpha}+\widetilde{\beta} r_{m, t(i)+1}\right)\right. \\
& -\frac{1}{n_{i}} \sum_{i=1}^{n_{i}}\left(1+\widetilde{\alpha}+\widetilde{\beta} r_{m, t(i)}\right)\left(1+\widetilde{\alpha}+\widetilde{\beta} r_{m, t(i)+1)}\right]^{2} \\
= & \min _{\widetilde{\alpha}, \widetilde{\beta}} \sum_{i=1}^{N}\left[\left((\alpha-\widetilde{\alpha})+(\beta-\widetilde{\beta}) r_{m, t(i)}+\overline{\varepsilon_{i}}\right)\left(1+\widetilde{\alpha}+\widetilde{\beta} r_{m, t(i)+1}\right)\right]^{2}
\end{aligned}
$$

This expression shows that the 'pricing error' $(\alpha-\widetilde{\alpha})+(\beta-\widetilde{\beta}) r_{m, t(i)}+\overline{\varepsilon_{i}}$ is multiplied by the compounding term $\left(1+\widetilde{\alpha}+\widetilde{\beta} r_{m, t(i)+1}\right)$. Asymptotically, the $\overrightarrow{\varepsilon_{i}}$ 's tend to zero and $\widetilde{\alpha}$ and $\widetilde{\beta}$ are consistent estimators of $\alpha$ and $\beta$. In a small sample, however, minimizing these 'compounded pricing errors' generates a tendency to bring the (positive) term $(1+\widetilde{\alpha}+$ $\left.\widetilde{\beta} r_{m, t(i)+1}\right)$ closer to zero. In particular, as shown in the simulations below, this leads to a downward bias for $\widetilde{\alpha}$. Moreover, the goal function in equation (9) is not globally convex because setting $\widetilde{\alpha}$ close to -1 gives a second local minimum (which may be lower than the correct minimum in a small sample). 
Note that discounting the cash flows back in time to the beginning of fund life leads to a similar bias but in the other direction, because many project investments happen after the inception date of the fund. To see this in our simplified example, we discount back to one period before the starting date of the project, in which case we can write the optimization in the simplified setup as follows (using equation (8))

$$
\begin{aligned}
= & \min _{\widetilde{\alpha}, \widetilde{\beta}} \sum_{i=1}^{N}\left[\frac{\left(1+\alpha+\beta r_{m, t(i)}+\overline{\varepsilon_{i}}\right)}{\left(1+\widetilde{\alpha}+\widetilde{\beta} r_{m, t(i)-1}\right)\left(1+\widetilde{\alpha}+\widetilde{\beta} r_{m, t(i)}\right)}\right. \\
& \left.-\frac{1}{\left(1+\widetilde{\alpha}+\widetilde{\beta} r_{m, t(i)-1}\right)}\right]^{2} \\
= & \min _{\widetilde{\alpha}, \widetilde{\beta}} \sum_{i=1}^{N}\left[\frac{(\alpha-\widetilde{\alpha})+(\beta-\widetilde{\beta}) r_{m, t(i)}+\overline{\varepsilon_{i}}}{\left(1+\widetilde{\alpha}+\widetilde{\beta} r_{m, t(i)-1}\right)\left(1+\widetilde{\alpha}+\widetilde{\beta} r_{m, t(i)}\right)}\right]^{2}
\end{aligned}
$$

Since we divide by $\left(1+\widetilde{\alpha}+\widetilde{\beta} r_{m, t(i)-1}\right)\left(1+\widetilde{\alpha}+\widetilde{\beta} r_{m, t(i)}\right)$, we obtain an upward bias for (in particular) $\widetilde{\alpha}$, which is confirmed by the simulation results. Moreover, this estimator suffers from numerical problems: since the denominator in (11) has a cubic dependence on $\widetilde{\alpha}$ and the numerator depends linearly on $\widetilde{\alpha}$, the goal function in (11) tends to zero as $\widetilde{\alpha} \rightarrow \infty$. Hence, the goal function is not globally convex. This is shown in Figure 1 in a more realistic setting (the simulation study in section 3.5). Using this method is therefore problematic in practice, especially if one does not have good starting values for the optimization algorithm. We label this second method the 'Net Present Value' (NPV) approach.

\subsection{An improved GMM-style approach}

The small sample bias that we document above comes from the extra compounding we do to bring all projects to the final liquidation date. We study three ways to cancel this effect. The idea is to construct estimators that are insensitive to the choice of discounting or compounding the cash flows. These methods are a modification of the GMM framework and are all statistical consistent (see appendix 1 for a formal proof). 


\subsubsection{Method 3: Public Market Equivalent approach (PME)}

Above, we minimized the distance between the final value of dividends (the value of our fund-of-funds) and the final value of the investments (the mimicking fund). An alternative option is to minimize the distance between the ratio of these two values (known as Public Market Equivalent, see Kaplan and Schoar, 2005) and unity. Asymptotically, this approach is consistent as it is based on the same moment condition (equation (4)) as the two methods above (see also appendix 1). However, small sample properties are different.

Estimation is then performed as follows

$$
\min _{\alpha, \beta} \sum_{i=1}^{N}\left[\frac{\overline{C V}{ }^{D_{i}}(\alpha, \beta)}{\overline{C V}^{T_{i}}(\alpha, \beta)}-1\right]^{2}
$$

In this case, it is irrelevant whether one discounts or compounds all cash flows since the discounting/compounding term affects the denominator and numerator in exactly the same way.

To study the small-sample bias, we again turn to the simplified case of equation (8). In this case the estimation can be rewritten as

$$
\begin{aligned}
& =\min _{\widetilde{\alpha}, \widetilde{\beta}} \sum_{i=1}^{N}\left[\frac{\left(1+\alpha+\beta r_{m, t(i)}+\overline{\varepsilon_{i}}\right) /\left(1+\widetilde{\alpha}+\widetilde{\beta} r_{m, t(i)-1}\right)\left(1+\widetilde{\alpha}+\widetilde{\beta} r_{m, t(i)}\right)}{1 /\left(1+\widetilde{\alpha}+\widetilde{\beta} r_{m, t(i)-1}\right)}-1\right]^{2} \\
& =\min _{\widetilde{\alpha}, \widetilde{\beta}} \sum_{i=1}^{N}\left[\frac{(\alpha-\widetilde{\alpha})+(\beta-\widetilde{\beta}) r_{m, t(i)}+\overline{\varepsilon_{i}}}{\left(1+\widetilde{\alpha}+\widetilde{\beta} r_{m, t(i)}\right)}\right]^{2}
\end{aligned}
$$

This method thus generates a 'discounting' bias since the pricing error is divided by

$\left(1+\widetilde{\alpha}+\widetilde{\beta} r_{m, t(i)}\right)$, leading to an upward bias for $\widetilde{\alpha}$ in particular. However, relative to the NPV-estimator, this bias will be smaller because there is less discounting than in equation (11). Also, since both the denominator and numerator depend linearly on $\widetilde{\alpha}$, the goal function does not tend to zero as $\widetilde{\alpha} \rightarrow \infty$ so that there is a unique optimum for this estimator. This is confirmed in section 3.5 in a more realistic setting. 


\subsubsection{Method 4: Natural Logarithm of PME approach (Log-PME)}

Another option is to minimize the distance between the log of the final value of dividends and the log of the final value of the investments. The underlying moment condition takes logs at both sides of equation (4). Estimation is performed as follows

$$
\min _{\alpha, \beta} \sum_{i=1}^{N}\left[\ln \left(\overline{C V}^{D_{i}}(\alpha, \beta)\right)-\ln \left(\overline{C V}^{T_{i}}(\alpha, \beta)\right)\right]^{2}
$$

In our simplified example, the estimator is the result of the following optimization

$$
\min _{\widetilde{\alpha}, \widetilde{\beta}} \sum_{i=1}^{N}\left[\ln \left(1+\alpha+\beta r_{m, t(i)}+\overline{\varepsilon_{i}}\right)-\ln \left(1+\widetilde{\alpha}+\widetilde{\beta} r_{m, t(i)}\right)\right]^{2}
$$

This equation shows that there is no discounting or compounding bias. However, equation (16) generates a small-sample convexity bias because $E\left[\ln \left(1+\alpha+\beta r_{m, t(i)}+\bar{\varepsilon}_{i}\right)\right]<$ $E\left[\ln \left(1+\alpha+\beta r_{m, t(i)}\right)\right]$. As discussed above, this bias disappears asymptotically since $\overline{\varepsilon_{i}}$ tends to zero as $n_{i} \rightarrow \infty$. In small samples, however, this creates a tendency to lower the

term $\left(1+\widetilde{\alpha}+\widetilde{\beta} r_{m, t(i)}\right)$, leading to a downward bias for $\widetilde{\alpha}$. In general, the estimator $\widetilde{\beta}$ will be biased as well, but quantitatively this bias is small (section 3.5 below). Like the PME method, this method does not suffer from numerical problems since this method is fully insensitive to the choice of discounting or compounding cash flows. This is confirmed by our simulations and empirical results. For example, we find a globally convex goal function in our simulations, as shown in Figure 2.

\subsubsection{Method 5: Exact Identification (Method of Moments)}

The final method is a simple method of moments where we set the number of fund-of-funds equal to the number of parameters $(N=2$ in case of the market model). Setting $N=2$ delivers a special case of all methods discussed above, since in this case all methods will give the same estimates. This is because in this setting the two moment conditions are matched exactly, so that it does not matter how the moment conditions are compounded or discounted. However, as discussed in the simple example in section 3.1.3, an important 
caveat is that with $N=2$ we can have multiple solutions for $\alpha$ and $\beta$. Another disadvantage is that reducing the number of moment conditions may lower the precision of the estimates. Intuitively, we anticipate that it will be difficult to estimate a beta from only 2 pairs of portfolio performance and realized market performance (one pair per moment condition).

In our simplified example, it is easy to show that solving the moment conditions in this case boils down to setting the pricing errors for the two FoFs to zero

$$
(\alpha-\widetilde{\alpha})+(\beta-\widetilde{\beta}) r_{m, t(i)}+\overline{\varepsilon_{i}}=0, i=1,2
$$

Then, as long as $r_{m, t(1)} \neq r_{m, t(2)}$ the estimators $\widetilde{\alpha}$ and $\widetilde{\beta}$ are unbiased. However, in a more realistic setting where the duration of projects is larger than one period, the

first-order conditions are not linear in $\widetilde{\alpha}$ and $\widetilde{\beta}$ anymore, because products of the form $\left(1+r_{f}+\widetilde{\alpha}+\widetilde{\beta} r_{m, t(i)}\right)\left(1+r_{f}+\widetilde{\alpha}+\widetilde{\beta} r_{m, t(i)+1}\right)$ will enter the pricing error formula. Hence, in general this method generates a small-sample nonlinearity bias, which is also present with the other 4 methods.

\subsection{Portfolio formation and inference}

In this section, we draw from the above analysis to discuss how to best form the portfolios of funds. Next, we describe a bootstrap methodology to make inference in our context. Finally, we discuss measures of goodness of fit.

\subsubsection{Portfolio formation}

The first order condition in equation (17) shows that in the one-period case, $\beta$ is identified if $r_{m, t(1)} \neq r_{m, t(2)}$, that is, if the different FoFs are subject to different market return shocks. It is useful to derive the first order conditions for a case where the two FoFs are formed such that each FoF has half of the projects in period $t(1)$ and half of the projects in period $t(2)$. In other words, both FoFs have projects in both periods with equal weights. In the simple one-period example, the first order conditions are

$$
(\alpha-\widetilde{\alpha})+\frac{1}{2}(\beta-\widetilde{\beta})\left(r_{m, t(1)}+r_{m, t(2)}\right)+\overline{\varepsilon_{i}}=0, i=1,2
$$


In this case, $\alpha$ and $\beta$ cannot be separately identified. As was already indicated by our simple example (section 3.1), this shows that it is important to create portfolio of funds (FoFs) that have as little overlap in time as possible, to allow for cross-sectional identification of $\beta$. We thus suggest to group funds by vintage year in practice.

Finally, we noted above that the bias is a direct function of the variance of $\overline{\varepsilon_{i}}=$ $\frac{1}{n_{i}} \sum_{j=1}^{n_{i}} \varepsilon_{i j}$, which is the average of the idiosyncratic shocks across projects within a fundof-funds. This suggests to group funds into funds-of-funds as much as possible. However, reducing the number of FoFs implies that the time-overlap between the FoFs becomes larger. When choosing the number of funds-of-funds, we thus face a trade off in terms of precision and bias. We will use a Monte Carlo simulation (section 3.5) to shed light on this trade-off.

\subsubsection{Inference and goodness of fit}

We have shown that a cross-section of cash flow streams is sufficient to consistently infer risk and abnormal return. Hence, not having the time series of market values does not prevent such estimation. However, the lack of a time series of market values prevent the direct estimation of the variance-covariance matrix. Hence, for inference, we rely on a cross-sectional bootstrapping technique to obtain standard errors.

We resample the funds with replacement within each fund-of-funds, and then re-estimate the alpha and the beta. By resampling at the fund level, we thus assume that the idiosyncratic shocks of projects are perfectly correlated within a given fund but idiosyncratic shocks to projects are uncorrelated between funds. Repeating the process 1,000 times yields the bootstrap distribution of alpha and beta. ${ }^{6}$

We have also performed a block bootstrapping that takes into account the correlation between funds within each fund-of-funds. We first divide funds within each fund-of-funds into eight blocks constructed by a $2 \times 2 \times 2$ sort on EU/US focus, fund size, and experience. Within each block, the funds are assumed to be perfectly correlated. The blocks are then drawn with replacement like the original bootstrapping. The results for block bootstrapping

\footnotetext{
${ }^{6}$ As discussed by Horowitz (2001), in some cases it is beneficial to 're-center' the moment conditions when performing the bootstrap analysis. We find similar standard errors when we re-center the moment conditions. We also find that a bootstrap bias-correction for GMM hardly changes the estimates (Horowitz, 2001).
} 
are almost identical and thus not reported.

In the empirical section, we discuss a diagnostic test for the assumption that idiosyncratic shocks of funds with different vintage years are independent. The results of this test support this independence assumption.

\subsection{Small-sample properties: A Monte Carlo Simulation}

As discussed above, our GMM-style methodology generates asymptotically consistent estimates of $\alpha$ and $\beta$ but we expect small-sample biases. To evaluate their magnitude and to evaluate the different methods, we run a Monte Carlo experiment.

We aim to mimic the size and characteristics of our main dataset (venture capital funds). At the beginning of year $=1980, \ldots, 1993,50$ funds are started. They all invest $\$ 1$ per project and start 3 projects per year for 5 years, so that a fund has 15 projects in total. ${ }^{7}$ The economy is specified as in Cochrane (2005b). That is, the quarterly growth in value of project $j$ of fund $i$ is assumed to be lognormally distributed:

$$
\ln \left(\frac{V_{i j, t+1}}{V_{i j, t}}\right)=\gamma+\ln R_{f, t}+\delta\left(\ln R_{m, t+1}-\ln R_{f, t}\right)+\eta_{i j, t+1}, \quad \eta_{i j, t+1} \sim N\left(0, \sigma^{2}\right)
$$

where $\eta_{i j, t}$ is i.i.d. normal across projects and over time. ${ }^{8}$ Following Cochrane (2005b), the probability that a project exits at time $t$ is given by the following logistic function $\frac{1}{1+e^{-a\left(\ln \left(V_{i j, t}\right)-b\right)}}$. That is, the project is more likely to exit as it reaches higher values. In addition, a project is also more likely to exit if it reaches a low value. The probability of exiting is then given by $\frac{k-V_{t}}{k}$, with $V_{t}<k$. We thus incorporate endogenous timing of cash flows in our setup. Finally, if a project is still alive after 5 years, it is liquidated and a dividend equals to its value is paid.

Following the remark in subsection 3.4, we group all the funds with the same vintage

\footnotetext{
${ }^{7}$ This number matches the venture capital sample that we describe below.

${ }^{8}$ As shown in Cochrane (2005b), the continuous limit of equation (19) can be used to obtain the $\alpha$ and $\beta$ for the CAPM in simple returns which gives $\beta=\delta$ and

$$
\alpha=\gamma+\frac{1}{2} \delta(\delta-1) \sigma_{m}^{2}+\frac{1}{2} \sigma^{2}
$$

where $\sigma_{m}^{2} \equiv V\left(\ln \left(R^{m}\right)\right)$.
} 
year into a fund-of-funds (FoF). We thus have 14 moment conditions (one for each vintage year). We set the risk-free rate to $4 \%$ p.a. and the log-return on the market index is drawn from a normal distribution with $12 \%$ mean and $15 \%$ volatility (matches S\&P 500 index distribution from 1980 to 2003). All the other parameter estimates are taken from Cochrane (2005b): $a=1, b=3.8, k=0.25, \sigma=0.86$. Alpha and beta are set to zero and one respectively to simplify exposure (results are not sensitive to the true alpha and beta).

Results are shown in Panel A of Table 1. The intuition developed above is confirmed. If we compound cash flows forward (NCV-approach) a small negative bias is present in alpha (4 basis points per month) whereas if we discount cash flows (NPV-approach) a positive bias of similar magnitude is present in alpha (5 basis points per month). Also consistent with the above arguments, the PME approach generates a bias in the same direction as the NPV approach but smaller ( 2 basis points per month). The best approach is log-PME. The bias is slightly negative (due to the convexity effect discussed in section 3.3.2) but negligible (1 basis point per month). In addition, both the standard deviation and inter-quartile range for the log-PME estimate are smaller than with any other method. Furthermore, the logPME approach estimates beta without any bias and with the highest precision compared to other methods. Finally, to implement the method of moments (method 5) we create two FoFs. The first FoF contains the first 7 vintage years, and the second FoF the next 7 vintage years. We find that this approach has significant biases in both alpha and beta. As explained above, by grouping vintage years we lose information on the relation between portfolio performance and the associated market performance, making it difficult to estimate beta.

As mentioned above, the bias of our estimates depends on the size of idiosyncratic shocks. We therefore show our results with a lower idiosyncratic volatility (Panel B) and with a higher idiosyncratic volatility (Panel C). The low volatility level is set to $25 \%$ per annum. This corresponds to the Ang, Hodrick, Xing and Zhang (2006) estimate for the highest idiosyncratic volatility quintile of US stocks and is slightly larger than the idiosyncratic volatility of the small growth stock portfolio of Fama-French (19\% p.a.). ${ }^{9}$ The high

\footnotetext{
${ }^{9}$ See Table 6 of Ang, Hodrick, Xing and Zhang (2006), which provides total volatility estimates across quintile portfolios. We correct these total volatilities for market volatility to obtain idiosyncratic volatility.
} 
idiosyncratic volatility level is simply about twice the benchmark case at $150 \%$ p.a.

Results show that, as suggested above, our estimate becomes very precise when idiosyncratic volatility is at the level of individual stocks (Panel B). All the methods provide unbiased estimates. Log-PME is still the most precise of all but the difference with the other methods is negligible. Turning to the high idiosyncratic volatility level, we see that the differences across methods are much larger. The NCV method gives an alpha of about $-50 \%$, which is obviously wrong. The problem comes from a convergence to a corner (and incorrect) solution close to $-100 \%$. In $75 \%$ of the simulations alpha converges to this near corner solution. The NPV method is better but generates an economically significant bias of 70 basis points per month. The PME method generates less than half that bias (24 basis

points per month). Finally, the log-PME is very clearly the best method with a bias of only 4 basis points per month despite the extremely high volatility.

Note that the return distribution departs from lognormal in a complex way given the various stopping rules. As a robustness check, we increase the maximum project duration from 5 to 7 years (using the benchmark volatility level). Panel D of Table 1 shows that the small-sample bias and precision hardly change relative to the benchmark case (Panel A).

In sum, despite the complex probability distribution and the fact that we do not use any distributional assumption, our approach finds estimates that are close to the true values of risk and abnormal returns. Our estimator is thus not only asymptotically consistent but its small-sample properties are good.

\section{Data}

We apply the methodology developed above to the estimation of risk and abnormal return of venture capital funds and buyout funds. In this section, we provide key institutional details, describe our data source, the content of our dataset, and our treatment of non-liquidated funds. 


\subsection{Data and institutional environment}

The private equity funds that we study are organized as limited partnerships and have a finite life (typically 10 years). This structure is by far the most common in this industry. Investors commit a certain amount of capital to a private equity fund. The fund "calls" money from investors at different points in time up to the amount committed. Similarly, funds distribute dividends at different point in time until its complete liquidation. The timing of these cash flows is typically unknown ex ante. The year when a fund starts is called vintage year. Funds report quarterly Net Asset Values (NAVs) but these are often equal to the amount invested. ${ }^{10}$

Data on both private equity fund cash flows and quarterly NAVs are from Thomson Venture Economics. Cash flows are net of fees as they are what investors have received and paid. This dataset is the most comprehensive source of financial performance of both US and European private equity funds and has been used in previous studies (e.g., Kaplan and Schoar, 2005) and covers an estimated $66 \%$ of both venture capital funds and buyout funds (Phalippou and Gottschalg, 2007).

We consider all funds (with size over $\$ 5$ million) raised between 1980 and 1993 as they have reached their normal liquidation age (10 years) at the end of our sample time period (2003). As discussed above, we construct venture capital fund-of-funds and buyout fundof-funds based on vintage years. We exclude vintage years with less than 10 funds; this excludes buyout funds raised between 1980 and 1983 but does not affect venture capital funds.

Descriptive statistics are reported in Table 2. We have 958 funds, of which 686 have a Venture Capital (VC) objective and 272 have a buyout (BO) objective. In total, we have 25,800 cash flows. Our descriptive statistics are similar to what has been reported in the literature.

\footnotetext{
${ }^{10}$ For further details on private equity fund contracts, see Axelson, Stromberg and Weisbach (2007), Gompers and Lerner (1999, 2000), Metrick and Yasuda (2007) and Phalippou (2007).
} 


\subsection{Estimating Final Market Values}

Table 2 shows that two thirds of the funds report a positive NAV at the end of our sample time period despite having passed their tenth anniversary. Existing work either treats these final NAVs as a final cash flow (Kaplan and Schoar, 2005) or writes them off (Phalippou and Gottschalg, 2007). One of the problems faced in the literature and which partly explains these simple choices is that the conversion of NAVs into a market value necessitates an estimate of risk.

In this paper, rather than making a judgement call, we estimate econometrically the relation between NAV and market value. Specifically, we take the fully liquidated funds at different ages, compute their realized market value (MV) as the net present value of subsequent cash flows where we discount with the pricing model estimated by our GMM method. Then, for each age a=10,11,12, and 13, we separately estimate the following model

$$
\ln \left(1+M V_{a, i}(\alpha, \beta)\right)=b_{a 0}+b_{a 1}^{\prime} X_{a, i}+\varepsilon_{a, i}
$$

The vector of explanatory variables $X_{a, i}$ includes $\ln (1+N A V)$, the log of fund size, the $\log$ of the time elapsed since the last dividend distribution, the log of the time elapsed since the last NAV update, and fund's performance multiple excluding NAV (sum of capital distributed divided by sum of capital invested); where all variables are computed at age $a$.

Results from the regression (21) are shown in Table 3 - Panel A. We find that a $1 \%$ increase in NAV leads to slightly less than $1 \%$ increase in market value and that this elasticity decreases with age. Large funds and better performing funds tend to have higher market values, hence more conservative accounting valuations. Funds that have not paid a dividend for a long time have lower market values. Similarly, the NAV of funds that have not updated their NAVs for a long time is significantly exaggerated. This variable is the most significant of all explanatory variables. The average time since last NAV update is 1.5 years. An increase to 2 years would decrease market value by about $10 \%$ everything else constant (taking the average coefficient across the 4 specifications).

Some descriptive statistics for fully-liquidated funds are shown in Table 3 - Panel B. The ratio of market value to NAV is between $100 \%$ at age 10 to $113 \%$ at age 13 . Hence, 
for the sample of liquidated funds, NAVs are overall close to market values. However, as several of the explanatory variables are statistically significant, we find that there are large cross-sectional differences.

The next step consists of predicting final market values for the non-liquidated funds by applying the regression coefficients from equation (21) to the fund characteristics of the non-liquidated funds. ${ }^{11}$ Results of the extrapolation are shown in Table 3 - Panel B. The model predicts small market values compared to NAVs. The ratio of total market values to total reported NAVs is between $21 \%$ (age 12) and $37 \%$ (age 10). Overall $70 \%$ of NAVs are written off according to the model. This is due to the different characteristics of nonliquidated funds. Non-liquidated funds have not paid any dividends for about 3.5 years while fully liquidated funds have on average paid a dividend 1 year ago. Similarly, non-liquidated funds have not updated their NAVs for 2.5 years while liquidated funds have updated their NAVs less than 6 months ago. ${ }^{12}$ As a consequence, the model predicts small market values. We thus provide evidence that NAVs of old and inactive funds largely overstate the true market value.

The results described above require a joint estimation setup. $M V_{a, i}(\alpha, \beta)$ depends on the discount rate, and is therefore a function of $\alpha$ and $\beta$. In turn, to apply our GMM methodology and estimate $\alpha$ and $\beta$, we need the estimate of $M V_{a, i}(\alpha, \beta)$ to run regression (21) and predict the final market value of the non-liquidated funds. Hence, we simultaneously estimate $\alpha$ and $\beta$ from the GMM equation (15) and the regression coefficients in (21). The results described above are those obtained when estimating a one-factor market model (which we call CAPM for convenience). We find similar coefficients for the Fama-French model.

\footnotetext{
${ }^{11}$ Beyond the 13th anniversary (typically the maximum duration of a fund), we observe only very few funds that have a positive NAV and are subsequently liquidated. For funds older than 13 years, we therefore predict the market value at the end of their 13th anniversary and use the coefficients from the age 13 regression. This predicted final market value is thus used as final dividend at age 13. This choice explains why most of the funds in the prediction sample are in the age 13 category $(\mathrm{N}=434)$.

${ }^{12}$ These results are driven by a large number of funds that do not update their NAV or pay any dividends for several years beyond age 10. This fact could be either a deliberate action of funds in an attempt to "hide" bad performance (Phalippou and Gottschalg, 2007, report that these funds tend to have the lowest performance), or result from a data entry convention (if a fund liquidates but investors do not report that event to TVE then TVE keeps on repeating the latest NAV forever). Unfortunately, we cannot obtain information from TVE on this issue.
} 


\section{$5 \quad$ Risk and Return Estimates}

In this section, we first report the estimates of risk and abnormal return of private equity funds using the log-PME methodology (section 5.1). In section 5.2, we investigate differences in $\alpha$ and $\beta$ across funds by allowing these parameters to be a function of fund characteristics like size and experience. Finally, in section 5.3, we present several robustness checks for the estimation setup and portfolio formation.

\section{$5.1 \quad$ Benchmark Results}

In section 3.5, we concluded that it was best to create one portfolio (fund-of-funds, FoF) per vintage year and to use the log-PME approach. This is what we do here in the empirical application. Note also that for each portfolio we add the cash flows across funds, hence, we value weight each fund within each FoF. Our estimate of risk and abnormal performance is thus for $\$ 1$ invested in either venture capital funds or buyout funds.

The results for the CAPM specification are shown in the first specification of Table 4 Panel A for venture capital funds and of Table 4 - Panel B for buyout funds. We find that venture capital funds have a significantly different risk profile than buyout funds. Venture capital funds have a market beta of 3.21 with standard error 0.22 . In contrast, buyout funds have a market beta of about 0.33 , estimated with a larger standard error of 0.38 .

To provide some intuition for these GMM estimates, we inspect the patterns in our data. Figure 3 shows the time series of average 'dividend yields' for venture capital funds and buyout funds. The dividend yield in month $t$ for fund $i$ is the sum of all dividends paid over the previous twelve months divided by fund size. To obtain an aggregate dividend yield, we take the average across all funds that are in their divestment phase, i.e. fund age is between 4 and 10 years. On the same graph, we plot the 5-year moving annual average of the S\&P 500 returns. The idea is that if the stock-market does well during 5 years which is the average duration of an investment - then a high (low) beta asset will distribute larger (smaller) dividends in the following year. On the figure, it is apparent that the first pick of the stock-market in 1995 and the rally of 1998-1999 goes hand-in-hand with a huge spike in dividend yield for venture capital funds. When the stock market went down the 
following three years, so did the dividends. Our high estimate for the venture capital beta reflects these features of the data. Interestingly, the same figure shows that buyout fund dividends are smoother across years. In addition, venture capital dividend yield fluctuates widely with a minimum of $5 \%$ and maximum of $80 \%$. In contrast, the dividend yield for buyout funds fluctuates between $5 \%$ and $25 \%$ per year and appears relatively flat. Figure 3 is thus consistent with our empirical estimates of risk.

The finding of low beta and steady dividend yield for buyout funds may be surprising. It is sometimes argued, however, that buyout funds hold companies that are in low beta industries. Hence, despite the mechanical effect of leverage on beta, buyout beta may be low. An additional argument is that buyout funds make many changes to the companies they purchase. The success of the changes operated by buyout funds may have little correlation with stock-market returns. This could drag the beta towards zero. It may be argued that the same holds for venture capital investments and yet their beta is high. A potential explanation for this could be that an active IPO market is more important for venture capital than for buyout. An active IPO market, in turn, is dependent on stock market returns. Hence, venture capital investments success is likely to be more stock-market dependent than buyout investment success. ${ }^{13}$

Note, however, that our estimates for buyout funds are less precise than for venture capital. In addition, while the venture capital beta estimate is very robust to changes in sample selection and method, this is less so for the buyout sample (section 5.3). This is probably due to the smaller sample for buyout funds. Also, compared to venture capital funds, buyout funds are more heterogeneous in terms of size, geographic focus (they are 50\%$50 \%$ Europe versus US focused while they are mainly US focused in venture capital), and investment type. ${ }^{14}$ In unreported results, we have attempted to capture such heterogeneity by making beta a function of observable characteristics (see also next section) but given

\footnotetext{
${ }^{13}$ Cao and Lerner (2007) find that once they are publicly listed, buyout backed companies have a beta of 1.3. However, the companies that go IPO may not be representative. Those that go public may have higher betas. In addition, the beta of the same company may be different when it is in the fund's hands and once it is listed.

${ }^{14}$ Buyout funds make some investments in public equity, some growth equity investments which resemble more late stage venture capital, and some management buyouts whose risk-return characteristics may differ from the rest.
} 
the low number of observations for buyout funds, the estimates are often imprecise on subsamples.

To assess the fit of the one-factor market model, we calculate for each of the 14 vintageyear portfolios a pricing error. Instead of just comparing the difference between the compounded value of dividends and investments, we focus on a 'monthly pricing error' for each FoF by calculating how much the alpha needs to be increased or decreased such that the value of dividends and investments are exactly equal to each other for this FoF. For venture capital funds, we then find that the average absolute pricing error across funds is $0.20 \%$ per month. Keeping in mind that part of this error represents idiosyncratic risk that is not fully averaged out at the portfolio level, this average error is economically small. For buyout funds, the average absolute error is larger at $0.56 \%$ per month. This higher pricing error is mainly driven by one vintage year. Excluding this year brings the average absolute error down to $0.35 \%$ but does not significantly affect the estimates.

As mentioned in section 3.4, standard errors are derived under the assumption that the idiosyncratic shocks are independent between funds that have different vintage years. We assess the validity of this assumption with the following diagnostic test. We calculate a pricing error for each of the 14 moment conditions (i.e. the difference between compounded value of dividends and compounded value of investments; $\overline{C V}^{D_{i}}(\alpha, \beta)-\overline{C V}^{T_{i}}(\alpha, \beta)$ in the notation of section 3.2). We conjecture that if there is significant cross-vintage-year dependence, it is likely that two successive vintage years (e.g. 1980 and 1981) have more correlated pricing errors than two vintage years that are further apart (e.g. 1980 and 1990). Hence, our proposed diagnostic is to test for the presence of autocorrelation in the time series of pricing errors. The results are reported in Table 4 below each specification. The error autocorrelation is negative in most specifications and never significantly positive. Together with the result that block-bootstrapping within a FoF generates similar results to random bootstrapping (as discussed in section 3.4), these results are a strong indication that the independence assumption we make for inference is reasonable on this dataset.

We also see that the precision of the estimates decreases when we add the FamaFrench factors (Table 4). Given that we perform a cross-sectional estimation, the parameter 
estimates are correlated to some extent and the correlation of these parameter estimates are higher for the three-factor model. This makes it harder to precisely pin down the different risk exposures. As shown in Table 4, the market betas are significant in the Fama-French specification, but we do not find significant exposure to the SMB and HML factors, except for the exposure of buyout funds to SMB. Nonetheless, the signs of the exposures make intuitive sense for venture capital funds as they resemble small growth stocks. Buyout funds tend to co-move more with large stocks.

\subsection{Return and fund characteristics}

The literature has shown that some fund characteristics are related to returns and it is thus important to incorporate these regularities in our estimations to increase precision. At the same time, we shed light on the nature of these regularities. Kaplan and Schoar (2005) find that fund returns (measured by Public Market Equivalent or IRR) are positively related to the fund size. Our framework allows us to investigate whether this effect is due to higher abnormal performance or higher risk exposures. We make alpha and beta a function of these characteristics using the following specification

$$
\begin{gathered}
\alpha=a_{0}+a_{\text {size }} * \ln (\text { fund size }) \\
\beta=b_{0}+b_{\text {size }} * \ln (\text { fund size })
\end{gathered}
$$

Next, we form size-sorted portfolios (i.e. fund-of-funds) for each vintage year. This allows us to pin down the effect of size from the cross-section of moment conditions. If we would use the 14 vintage-year portfolios, size effects would only be identified to the extent that funds with different vintage year have different size. We thus form 2 portfolios per vintage year, sorted on size.

We show results in specifications 3 to 6 in Table 4 . We first include size in the alpha specification only (specifications 3 and 4) and confirm that the performance is positively and significantly related to size. Like Kaplan and Schoar (2005), we find that this result is highly significant for venture capital funds and weaker for buyout funds. 
Next, we allow the beta to depend on size. For venture capital funds, the size effect in alpha becomes insignificant while the size effect in beta is positive and significant. At the bottom of the panel we show economic magnitudes. We display the alpha and beta evaluated at the first size-quartile (small) and third size-quartile (large). For alpha, there is hardly any difference (alpha is $-1.34 \%$ for small funds and $-1.24 \%$ for large funds). For beta, however, the beta of small funds is 2.04 while it is 2.74 for large funds. The spreads are similar in the Fama-French specification. For buyout funds, the size effect in alpha actually becomes negative once we control for size effects in beta. The beta of buyout funds depends significantly on fund size. It is significant at the $1 \%$ level for the CAPM specification and at the $5 \%$ level for the Fama-French specification.

In sum, we find that large funds' higher returns can be attributed to higher level of systematic risk rather than abnormal performance. In unreported results, we have also examined whether fund experience is related to alpha and beta. We have used fund sequence as a measure of experience as in Kaplan and Schoar (2005). We found no significant relation between experience and alpha or beta.

\subsection{Robustness}

In this section, we investigate the robustness of our results. We first show results with a different treatment of NAVs. Next, we show results for different samples and different methodological choices. Finally, we discuss the inclusion of option-type features in our framework.

\subsubsection{NAV treatment}

We begin by re-estimating abnormal return and risk with i) final NAVs treated as fair market value (as in Kaplan and Schoar, 2005) and with ii) writing final NAVs off (as in Phalippou and Gottschalg, 2007). That is, we do not jointly estimate the final value of the fund and the risk profile but, instead, make a simple assumption for the final value of funds. Table 5 shows the results. VC beta decreases from 3.45 (final NAV treated as correct) to 2.98 (final NAV written off) in the CAPM specification. The estimate we find in the main 
analysis is between these two values (3.21 for the CAPM specification). Similar results are observed for buyout funds. Interestingly, the effect on abnormal performance is minimal. This is because beta offsets the effect of writing off NAVs. As mentioned above final NAVs are relatively large. Writing them off, therefore, should reduce performance substantially. However, writing them off also drives beta downwards. Consequently, the effect on alpha is minimal. For venture capital, alpha changes from $-1.08 \%$ per month to $-1.27 \%$ per month in the CAPM specification. The change in alpha is larger for buyout funds but not significant. Alpha changes from $0.37 \%$ per month to $0.62 \%$ per month in the CAPM specification.

\subsubsection{Change in empirical design}

Table 6 shows estimates of alpha and beta (CAPM model) for different samples and different methodological choices. ${ }^{15}$ On the left hand side, we show results for our benchmark case where the moment conditions are weighted by the number of funds in the FoF. On the right hand side, we show results when moment conditions are value weighted. We use the log-PME method for all estimations except for one case where we use the PME method. The default results (those shown in Table 4) are shown on the left hand side of the first line (alpha is $-1.24 \%$ and beta is 3.21 for $\mathrm{VC}$ and alpha is $0.49 \%$ and beta is 0.33 for $\mathrm{BO}$ ).

The first result is that value weighting the moment conditions instead of equally weighting them (as in Table 4) does not substantially change the estimated risk and abnormal performance for venture capital, while for buyout funds the estimated beta is typically larger in case of value weighting.

The second result is that varying the number of fund-of-funds (FoFs) has little impact on the estimates. For each vintage year, we sort funds by size and create either 2, 3 or 4 portfolios. Irrespective of how many portfolios we create, we find similar beta estimates. A partial exception is for BOs for which beta changes from 0.57 to 0.28 when moving from 2 to 3 FoFs per vintage year. This may be due to the lower number of buyout funds which means that as the number of portfolio increases the number of funds in each portfolio quickly decreases towards unity. This is also an indication that our estimates of BO fund risk and

\footnotetext{
${ }^{15}$ Each bootstrap calculation takes a day. Therefore, we do not report standard errors in this table.
} 
abnormal performance are not as precise as they are for $\mathrm{VC}$ funds.

Our third result is that estimates obtained by the PME method are similar to those obtained by the log-PME method. This is an indication that the PME and log-PME estimates are essentially not affected by small-sample biases. As we saw above, the PME method introduces an upward bias in alpha whereas the log-PME method introduces a small negative bias. If our sample is large enough then the estimates provided by the two methods are similar indicating that small-sample biases are minimal. For VC, alpha is $-1.20 \%$ with the PME method and $-1.24 \%$ with the log-PME method. These values are respectively $-1.22 \%$ and $-1.15 \%$ if we value weight the moment conditions. Consistent with the above results, the estimates are less stable for BO funds. Alpha is $0.97 \%$ with the PME method and $0.49 \%$ with the log-PME method $(0.46 \%$ and $0.06 \%$ respectively if we value weight the moment conditions.) Combined with the confidence interval we obtain for the benchmark estimate of the buyout beta (Table 4), it seems likely that the true buyout beta is between zero and one, which is an interesting result but, unfortunately, it is difficult to give a more precise point estimate for BO funds. Again, this may be due to some uncaptured heterogeneity (omitted factors) across BO funds or the smaller sample size for buyouts.

Our fourth result is that changing the time period does not significantly change estimates. Again, this is especially true for VC funds. Given the nature of our data, we provide a sense of the impact of our choice of the time period (funds raised between 1980 and 1993) by adding and removing one vintage year.

Our fifth result is that the sub-sample of US funds has similar risk-return profiles as the universe of funds. As non-US focused funds are a minority (especially in venture capital), we cannot test for whether the risk profile is the same in the US-focused sample versus the non-US focused sample. We can, however, run the estimation on the sub-sample of US funds as a robustness test and as indicative evidence on whether US-focused funds offer a different risk-return profile or not. We find that US-focused venture capital funds appear only slightly riskier and have a slightly higher alpha than the universe. Again, one should keep in mind that they represent the large majority of the universe. For buyout funds, where the sample is evenly split between US and non-US, it is the opposite. US-focused 
funds have higher alphas and lower betas. However, the sample becomes quite small when we separate US funds.

Finally, we run our estimations using different benchmark factor portfolios. We begin by using a different market portfolio for the non-US focused funds. In the above analysis we have used one market portfolio for all funds. Implicitly we have assumed that financial markets are integrated. We now assume that financial market are perfectly segmented and thus use non-US stock indices for non-US focused funds (with returns in US dollars to be consistent with the cash flow currency). The indices come from the website of Kenneth French. We use either the Europe index or the UK index (as most non-US funds are UKbased). For venture capital, the beta increases slightly from 3.21 (benchmark case) to 3.76 with the Europe index and 3.57 with the UK index. The alpha, however, increases slightly compared to the benchmark case. For buyout funds, a similar result is obtained. Next, we use the Nasdaq for venture capital funds. We find a lower beta (1.55 instead of 3.21) and a higher alpha (-0.55\% versus $-1.24 \%)$. This result indicates that $\mathrm{VC}$ funds performance is more closely related to that of the Nasdaq than that of the S\&P 500. This means that part of the large beta we find for the VC funds can be attributed to the fact that VC investments resemble Nasdaq stocks, which, themselves, have a high beta. This is confirmed when we use the small-growth portfolio of Fama-French. There, we also obtain a similar beta as the one obtained with the Nasdaq (1.70) but the alpha with respect to the small-growth portfolio is positive. The small growth portfolio has had historically a very low performance which is difficult to explain. This result shows that although they co-move closely with small-growth stocks, VC funds have a better performance than small-growth stocks. This result is similar to what Cochrane (2005b) finds with venture capital projects.

In sum, the robustness checks show that the VC results are robust and not subject to small-sample biases. In contrast, the buyout sample is smaller and reliable inference appears more difficult. 


\subsubsection{Option-type behavior in private equity}

As a final robustness check, we analyze to what extent the payoffs of private equity projects resemble those of options. At first sight, one could consider including an option return as an additional factor as commonly done in the hedge fund literature, or including a nonlinear return function like $\max \left(R_{m, t}, 0\right)$ in the pricing model. However, in contrast to hedge fund investments, private equity projects are long-term and it is thus unlikely that a monthly option return or a nonlinear function of the market return will capture the long-term nature of these projects.

Instead, we have incorporated one of the main features of long-term options in our setup, which is that the beta of an option changes with its moneyness. For example, in the Black-Scholes model the CAPM-beta of a call option equals

$$
\beta_{c}=\frac{S}{C} \mathcal{N}\left(d_{1}\right) \beta_{s}
$$

These Black-Scholes betas of call options decrease as the stock price increases, or, equivalently, when the option gets more in-the-money. Hence, if private equity projects resemble call options, the beta of private equity funds should vary with the moneyness of the option. In this case, the fund's $\beta$ can be approximated by a parametric function of the moneyness level. In particular, to mimic the beta of call options, we model the $\beta_{t}$ as follows

$$
\beta_{t}=\beta_{0}+\beta_{1} \log \frac{S_{t}}{S_{0}}
$$

where $S_{t}$ is the value of the stock market index at period $t$ (so $\log \frac{S_{t}}{S_{0}}$ is just the multiperiod return), and $S_{0}$ denoting the value of the stock market index at the beginning of the funds' vintage year ( $S_{0}$ will then vary across funds). If projects are similar to long-term call options their moneyness should depend on the long-term equity index performance $\left(\beta_{1}<0\right)$. In unreported results, we do not find evidence that $\beta_{1}$ differs significantly from zero. Of course, it may be that the option-type features of private equity funds are more subtle than modelled here. Finding the best model to capture option-type features of private equity funds is beyond the scope of this paper. 


\section{Conclusion}

We develop a new econometric methodology to estimate the risk and return of an asset using cash flow data. We then apply it to a sample of private equity funds. The GMM-type methodology we device is based on moment conditions that state that expected discounted dividends should equal expected discounted investments, where the discounting is done using a factor pricing model of which the parameters are to be estimated. This methodology does not use the self reported, stale and noisy intermediary Net Asset Values of funds, but instead uses data on fund investments and dividends. An advantage of our approach is that it allows us to leave the return distribution unspecified. This is an appealing feature as the return distribution is not directly observable given the lack of a time-series of market values. The method is asymptotically consistent and we show how to optimize the small sample performance by constructing appropriate moment conditions and fund portfolios. A simulation study shows that the small-sample properties are satisfactory.

We find that venture capital funds have a high CAPM-beta, while buyout funds have a much lower CAPM-beta. Venture capital funds have a significantly negative alpha. Buyout funds have a slightly positive alpha, but it is close to zero and statistically insignificant. We also find that the Net Asset Values reported by funds that are inactive (no cash flows and no updating of Net Asset Values) near the end of their life are highly upward biased estimates of their market value. Specifically, using a regression approach, we find that the final market values of inactive funds that are 10 to 13 years old are about $30 \%$ of their selfreported Net Asset Values. We incorporate the results of this regression in our estimation of abnormal performance and risk exposure. The flexibility of our GMM model also enables us to study the interaction between the characteristics of the funds and their alpha and beta. We find that larger fund have similar abnormal returns as smaller funds but have higher level of systematic risk. Finally, our method can be used for other limited life nontraded private partnerships (e.g. mezzanine debt funds and some real estate funds) and for corporate investments (the CFO observes a stream of cash flows from a division/project but no market values). 


\section{Appendix 1: GMM with nonlinear functions}

We derive the asymptotic behavior of both the PME estimator and the log-PME estimator. We follow the standard way of deriving asymptotic normality of the GMM estimator. Using general notation, the standard GMM moment condition can be written as

$$
E\left(f\left(\theta_{0}, x_{i}\right)\right)=0
$$

where $f(.,$.$) is a k$-dimensional function. Let $g_{N}(\theta)=1 / N \sum_{i=1}^{N} f\left(\theta, x_{i}\right)$. The GMM estimator is $\widehat{\theta}_{N}=\arg \min g_{N}(\theta)^{\prime} W_{N} g_{N}(\theta)$, with $W_{N}$ a weighting matrix. For our PME and log-PME estimators, the moment condition is

$$
h\left(E\left(f\left(\theta_{0}, x_{i}\right)\right)\right)=h(0)
$$

Normalizing $h(0)=0$ (without loss of generality) our estimator is equal to $\widehat{\theta}_{N}=$ $\arg \min _{\theta} h\left(g_{N}(\theta)\right)^{\prime} W_{N} h\left(g_{N}(\theta)\right)$. Applying the mean value theorem we have

$$
h\left(g_{N}\left(\widehat{\theta}_{N}\right)\right)=h\left(g_{N}\left(\theta_{0}\right)\right)+\frac{\partial h\left(g_{N}\left(\widetilde{\theta}_{N}\right)\right)^{\prime}}{\partial \theta}\left(\widehat{\theta}_{N}-\theta_{0}\right)
$$

where $\widetilde{\theta}_{j}$ is between $\theta_{0, j}$ and $\widehat{\theta}_{N, j}$. Then, using the first order condition $\frac{\partial h\left(g_{N}\left(\widehat{\theta}_{N}\right)\right)}{\partial \theta^{\prime}} W_{N} h\left(g_{N}\left(\widehat{\theta}_{N}\right)\right)=$ 0 , and premultiplying the above equation by $\frac{\partial h\left(g_{N}\left(\widehat{\theta}_{N}\right)\right)}{\partial \theta^{\prime}} W_{N}$ gives

$$
0=\frac{\partial h\left(g_{N}\left(\widehat{\theta}_{N}\right)\right)}{\partial \theta^{\prime}} W_{N} h\left(g_{N}\left(\theta_{0}\right)\right)+\frac{\partial h\left(g_{N}\left(\widehat{\theta}_{N}\right)\right)}{\partial \theta^{\prime}} W_{N} \frac{\partial h\left(g_{N}\left(\widetilde{\theta}_{N}\right)\right)^{\prime}}{\partial \theta}\left(\widehat{\theta}_{N}-\theta_{0}\right)
$$

which can be rewritten as

$$
\sqrt{N}\left(\widehat{\theta}_{N}-\theta_{0}\right)=-\left(\frac{\partial h\left(g_{N}\left(\widehat{\theta}_{N}\right)\right)}{\partial \theta^{\prime}} W_{N} \frac{\partial h\left(g_{N}\left(\widetilde{\theta}_{N}\right)\right)^{\prime}}{\partial \theta}\right)^{-1} \frac{\partial h\left(g_{N}\left(\widehat{\theta}_{N}\right)\right)}{\partial \theta^{\prime}} W_{N} \sqrt{N} h\left(g_{N}\left(\theta_{0}\right)\right)
$$

Under standard regularity conditions, the delta-method implies that $\sqrt{N} h\left(g_{N}\left(\theta_{0}\right)\right)$ has an asymptotically normal distribution and the premultiplying weighting matrices converge to their probability limits, so that the estimator is consistent and asymptotically normal. 


\section{References}

[1] Ang, A., R. Hodrick, Y. Xing and X. Zhang, 2006, The Cross-Section of Volatility and Expected Returns, Journal of Finance, 51, 1, 259-299.

[2] Axelson, U., P, Stromberg and M. Weisbach, 2007, Why are Buyouts Levered: The Financial Structure of Private Equity Firms, Journal of Finance, forthcoming.

[3] Cao, J., and J. Lerner, 2007, The Performance of Reverse Leveraged Buyouts, working paper.

[4] Cochrane, J., 2005a, Asset Pricing, Princeton University Press.

[5] Cochrane, J., 2005b, The risk and return of venture capital, Journal of Financial Economics, 75, 3-52.

[6] Fama, E.F. and K.R. French, 1993, Common risk factors in the returns on bonds and stocks, Journal of Financial Economics, 33, 3-56.

[7] Gompers, P.A. and J. Lerner, 1999, The venture capital cycle, Cambrige: MIT Press.

[8] Gompers, P.A. and J. Lerner, 2000, Money chasing deals? The impact of fund inflows on private equity valuations, Journal of Financial Economics, 50, 281-325.

[9] Horowitz, J., 2001, The Bootstrap, Handbook of Econometrics, vol V, chapter 52.

[10] Jensen, M., 1968, The performance of mutual funds in the period 1945-1964, Journal of Finance, 23 (2), 389-416.

[11] Jones, C. and M. Rhodes-Kropf, 2004, The price of diversifiable risk in venture capital and private equity, Working paper, Columbia University.

[12] Kaplan, S.N. and A. Schoar, 2005, Private equity performance: Returns, persistence, and capital flows, Journal of Finance, 60,1791-1822.

[13] Korteweg, A. and M. Sorensen, 2008, Risk and return of infrequently-traded assets: A Bayesian selection model of venture capital, Working paper, Standard GSB and Chicago GSB. 
[14] Metrick, A. and A. Yasuda, 2007, The economics of private equity funds, working paper, University of Pennsylvania.

[15] Moskowitz, T. and A. Vissing-Jorgensen, 2002, The Private Equity Premium Puzzle, American Economic Review, 92, 745-778.

[16] Phalippou, L., 2007, Investing in private equity funds: A survey, CFA Institute Literature Survey Series

[17] Phalippou, L., 2008, Risk and Return of Private Equity Investments: An overview. Wiley/Blackwell's Companion to Private Equity, edited by Douglas Cumming, forthcoming.

[18] Phalippou, L. and O. Gottschalg, 2007, The performance of private equity funds, Review of Financial Studies, forthcoming. 


\section{Table 1: Monte Carlo Simulations}

This table shows results from a Monte Carlo simulation of a Cochrane (2005b) economy. Each year (from 1980 to 1993), a batch of 50 funds enters the economy. Each fund invests \$1 per project and starts 3 projects per year for 5 years. The project return follows a log-CAPM with risk-free rate of $4 \%$, equity risk premium of $8 \%$, and (annual) market volatility of $15 \%$. The probability of exit is computed each quarter using Cochrane's parameter estimates ( $a, b$, and $k$ equals to $1,3.8$ and 25\% respectively in his notation). Projects have a maximum life of either 5 years (Panels A, B and C) or 7 years (Panel D). 1000 economies are simulated and we set the true alpha to zero and beta to one. For each economy, 5 estimation methods are executed (Net Compounded Value, Net Present Value, Public Market Equivalent, Log Public Market Equivalent and Methods of Moments; see section 3.3). The mean, standard deviation, and inter-quartile range of the 1,000 estimated pair of parameters (alpha, beta; monthly frequency) are displayed. In panel A, the idiosyncratic volatility is set to $86 \%$ p.a. (Cochrane's estimate). In Panels B and C, it is set to 25\% and 150\% p.a. respectively. Panel D reports results when the maximum duration for project is 7 years with $86 \%$ volatility p.a.

Panel A: Benchmark

\begin{tabular}{|c|c|c|c|c|c|}
\hline & $\mathrm{NCV}$ & NPV & PME & Log-PME & $\mathrm{MM}$ \\
\hline Mean Alpha & $-0.04 \%$ & $0.05 \%$ & $0.02 \%$ & $-0.01 \%$ & $0.07 \%$ \\
\hline Std Alpha & $0.23 \%$ & $0.20 \%$ & $0.20 \%$ & $0.19 \%$ & $0.57 \%$ \\
\hline Inter-Quartile & {$\left[\begin{array}{lll}-0.15 \% & 0.07 \%\end{array}\right]$} & {$[-0.06 \% \quad 0.15 \%]$} & {$\left[\begin{array}{lll}-0.08 \% & 0.12 \%\end{array}\right]$} & {$\left[\begin{array}{lll}-0.10 \% & 0.09 \%\end{array}\right]$} & {$\left[\begin{array}{lll}-0.13 \% & 0.19 \%\end{array}\right]$} \\
\hline Mean Beta & 1.00 & 0.98 & 1.00 & 1.00 & 0.93 \\
\hline Std Beta & 0.36 & 0.31 & 0.30 & 0.29 & 0.82 \\
\hline Inter-Quartile & {$\left[\begin{array}{ll}0.83 & 1.16\end{array}\right]$} & {$\left[\begin{array}{ll}0.81 & 1.13\end{array}\right]$} & {$\left[\begin{array}{ll}0.85 & 1.15\end{array}\right]$} & {$\left[\begin{array}{ll}0.85 & 1.14\end{array}\right]$} & {$\left[\begin{array}{ll}0.70 & 1.24\end{array}\right]$} \\
\hline
\end{tabular}


Panel B: Low volatility economy

\begin{tabular}{|c|c|c|c|c|c|}
\hline & NCV & NPV & PME & Log-PME & MM \\
\hline Mean Alpha & $-0.00 \%$ & $0.00 \%$ & $0.00 \%$ & $-0.00 \%$ & $0.00 \%$ \\
\hline Std Alpha & $0.04 \%$ & $0.03 \%$ & $0.03 \%$ & $0.03 \%$ & $0.14 \%$ \\
\hline Inter-Quartile & {$\left[\begin{array}{ll}-0.02 \% & 0.02 \%\end{array}\right]$} & {$\left[\begin{array}{ll}-0.01 \% & 0.02 \%\end{array}\right]$} & {$\left[\begin{array}{lll}-0.01 \% & 0.02 \%\end{array}\right]$} & {$\left[\begin{array}{ll}-0.01 \% & 0.01 \%\end{array}\right]$} & {$\left[\begin{array}{ll}-0.02 \% & 0.03 \%\end{array}\right]$} \\
\hline Mean Beta & 1.00 & 1.00 & 1.00 & 1.00 & 1.00 \\
\hline Std Beta & 0.06 & 0.05 & 0.05 & 0.05 & 0.24 \\
\hline Inter-Quartile & {$\left[\begin{array}{ll}0.97 & 1.03\end{array}\right]$} & {$\left[\begin{array}{ll}0.98 & 1.02\end{array}\right]$} & {$[0.98$ 1.02] } & {$[0.98$ 1.02] } & {$\left[\begin{array}{ll}0.95 & 1.05\end{array}\right]$} \\
\hline
\end{tabular}

Panel C: High volatility economy

\begin{tabular}{|c|c|c|c|c|c|}
\hline & NCV & NPV & PME & Log-PME & MM \\
\hline Mean Alpha & $-49.37 \%$ & $0.69 \%$ & $0.24 \%$ & $-0.04 \%$ & $0.30 \%$ \\
\hline Std Alpha & $29.58 \%$ & $1.78 \%$ & $0.72 \%$ & $0.55 \%$ & $1.35 \%$ \\
\hline Inter-Quartile & {$[-68.1 \%-2.14 \%]$} & {$\left[\begin{array}{lll}0.04 \% & 0.90 \%\end{array}\right]$} & {$[-0.17 \% 0.53 \%]$} & {$\left[\begin{array}{lll}-0.37 \% & 0.22 \%\end{array}\right]$} & {$\left[\begin{array}{lll}-0.36 \% & 0.62 \%\end{array}\right]$} \\
\hline Mean Beta & 0.33 & 0.66 & 0.97 & 0.95 & 0.86 \\
\hline Std Beta & 1.16 & 1.26 & 1.04 & 0.80 & 1.78 \\
\hline Inter-Quartile & {$\left[\begin{array}{ll}-0.09 & 0.36\end{array}\right]$} & {$\left[\begin{array}{ll}0.15 & 1.25\end{array}\right]$} & {$\left[\begin{array}{ll}0.44 & 1.51\end{array}\right]$} & {$\left[\begin{array}{ll}0.53 & 1.41\end{array}\right]$} & [0.06 1.83] \\
\hline
\end{tabular}

Panel D: Robustness - Maximum project duration increased to 7 years with benchmark volatility

\begin{tabular}{|c|c|c|c|c|c|}
\hline & NCV & NPV & PME & Log-PME & MM \\
\hline Mean Alpha & $-0.04 \%$ & $0.06 \%$ & $0.03 \%$ & $-0.00 \%$ & $0.08 \%$ \\
\hline Std Alpha & $0.22 \%$ & $0.21 \%$ & $0.20 \%$ & $0.20 \%$ & $0.57 \%$ \\
\hline Inter-Quartile & {$\left[\begin{array}{lll}-0.14 \% & 0.08 \%\end{array}\right]$} & {$[-0.04 \% 0.16 \%]$} & {$\left[\begin{array}{ll}-0.06 \% & 0.13 \%\end{array}\right]$} & {$\left[\begin{array}{lll}-0.09 \% & 0.09 \%\end{array}\right]$} & {$[-0.13 \% 0.19 \%]$} \\
\hline Mean Beta & 1.00 & 0.96 & 1.00 & 1.00 & 0.95 \\
\hline Std Beta & 0.35 & 0.33 & 0.32 & 0.31 & 0.86 \\
\hline Inter-Quartile & {$\left[\begin{array}{ll}0.81 & 1.13\end{array}\right]$} & {$\left[\begin{array}{ll}0.79 & 1.11\end{array}\right]$} & [0.83 1.13] & [0.84 1.13] & {$\left[\begin{array}{ll}0.64 & 1.25\end{array}\right]$} \\
\hline
\end{tabular}




\section{Table 2: Descriptive Statistics}

This table shows descriptive statistics for our sample. We report: (i) the average and the median of the amount committed to funds in million of 2003 U.S. dollars (size); (ii) the total final Net Asset Value reported (December 2003), total capital distributed and total capital invested; (iii) the overall multiple (sum NAV + sum Distributed) / (sum Invested); (iv) the proportion of first time funds; (v) the proportion of non-US focused funds; (vi) the proportion of funds with positive final Net Asset Value; and (vii) the number of cash flows and the number of funds.

\begin{tabular}{lcrrr}
\hline & & \multicolumn{1}{c}{ All funds } & Venture Capital & Buyout \\
\cline { 3 - 5 } Mean size & (\$ million) & 170.40 & 90.86 & 371.02 \\
Median size & (\$ million) & 63.98 & 51.82 & 133.38 \\
Sum NAV & (\$ billion) & 27.93 & 8.08 & 19.87 \\
Sum Distributed & (\$ billion) & 209.69 & 81.40 & 128.69 \\
Sum Invested & (\$ billion) & 119.89 & 39.57 & 80.50 \\
Multiple & & 1.98 & 2.26 & 1.85 \\
First time funds & & $49 \%$ & $46 \%$ & $57 \%$ \\
Non-US funds & $29 \%$ & $22 \%$ & $47 \%$ \\
Funds with positive final NAV & $64 \%$ & $63 \%$ & $64 \%$ \\
Number of cash-flows & 25,800 & 16,859 & 8,941 \\
\multicolumn{2}{l}{ Number of funds } & 958 & 686 & 272 \\
\hline
\end{tabular}




\section{Table 3: Final Fund Market Value Estimates}

Panels A shows the estimated relation between fund market value (MV) and fund characteristics for the sample of liquidated funds. Fund characteristics include reported Net Asset Value (NAV), fund size, time elapsed since last dividend distribution (LastDiv) and since last NAV change (LastNAV), and Profitability Index (present value of dividends over present value of takedowns). Market Values (MV) at a given age is computed as the present value of the subsequently realized cash flows. $t$-statistics are reported below for each coefficient in italics. The estimation is done separately for each age $\left(10^{\text {th }}\right.$ anniversary to $13^{\text {th }}$ anniversary). Panel B shows summary statistics of the liquidated sample and nonliquidated sample including the predicted Market Values computed from the model in Panel A.

Panel A: Market values as a function of fund characteristics - liquidated sample

\begin{tabular}{|c|c|c|c|c|}
\hline & \multicolumn{4}{|c|}{ Dependent variable: $\ln$ (Market Value) } \\
\hline & Age 10 & Age 11 & Age 12 & Age 13 \\
\hline \multirow[t]{2}{*}{ Constant } & -0.06 & -0.11 & -0.42 & -0.35 \\
\hline & -0.28 & -0.39 & -1.55 & -0.98 \\
\hline \multirow[t]{2}{*}{$\ln (1+N A V)$} & ${ }^{* * *} 0.89$ & ${ }^{* * *} 0.84$ & ${ }^{* * *} 0.83$ & ${ }^{* * *} 0.73$ \\
\hline & 19.30 & 16.50 & 16.32 & 11.68 \\
\hline \multirow[t]{2}{*}{$\ln ($ Size $)$} & 0.09 & ${ }^{*} 0.12$ & ${ }^{* *} 0.13$ & ${ }^{*} 0.13$ \\
\hline & 1.56 & 1.80 & 2.10 & 1.79 \\
\hline \multirow[t]{2}{*}{$\ln ($ LastDiv) } & ${ }^{* *}-0.09$ & ${ }^{*}-0.10$ & -0.03 & ${ }^{* *}-0.16$ \\
\hline & -2.00 & -1.86 & -0.56 & -2.11 \\
\hline \multirow[t]{2}{*}{ ln(LastNAV) } & ${ }^{* * *}-0.25$ & ${ }^{* * *}-0.22$ & ${ }^{* * *}-0.28$ & ${ }^{* * *}-0.18$ \\
\hline & -5.88 & -4.26 & -5.08 & -2.55 \\
\hline \multirow[t]{2}{*}{ Profitability Index } & -0.03 & 0.06 & 0.14 & ${ }^{* * *} 0.36$ \\
\hline & -0.60 & 0.60 & 1.25 & 2.65 \\
\hline Adj. R-square & 0.68 & 0.66 & 0.70 & 0.65 \\
\hline N-observations & 280 & 226 & 182 & 136 \\
\hline
\end{tabular}


Panel B: Summary Statistics

\begin{tabular}{|c|c|c|c|c|c|c|c|c|c|}
\hline & & \multicolumn{4}{|c|}{ Liquidated funds } & \multicolumn{4}{|c|}{ Non-liquidated funds } \\
\hline & & Age 10 & Age 11 & Age 12 & Age 13 & Age 10 & Age 11 & Age 12 & Age 13+ \\
\hline NAV & - Mean & 35.32 & 30.96 & 21.15 & 19.76 & 78.47 & 48.55 & 56.09 & 55.89 \\
\hline Size & - Mean & 121.21 & 122.77 & 122.08 & 123.42 & 234.81 & 202.30 & 140.89 & 203.93 \\
\hline LastDiv & - Mean & 14.00 & 12.75 & 11.97 & 11.40 & 37.09 & 36.58 & 57.46 & 41.03 \\
\hline LastNAI & I - Mean & 7.39 & 5.82 & 5.60 & 5.26 & 22.22 & 23.54 & 37.62 & 29.77 \\
\hline PI & - Mean & 0.90 & 0.92 & 0.94 & 0.99 & 0.82 & 0.94 & 0.59 & 0.81 \\
\hline \multicolumn{2}{|c|}{ NAV/Size } & 0.23 & 0.16 & 0.09 & 0.07 & 0.33 & 0.24 & 0.40 & 0.27 \\
\hline \multicolumn{2}{|c|}{ MV/NAV } & 1.00 & 1.00 & 1.06 & 1.13 & & & & \\
\hline \multicolumn{2}{|c|}{ Extrapolated-MV/NAV } & & & & & 0.37 & 0.32 & 0.21 & 0.29 \\
\hline N_obs & & 280 & 226 & 182 & 136 & 79 & 50 & 50 & 434 \\
\hline
\end{tabular}




\section{Table 4: Risk and Abnormal Performance of Private Equity Funds}

This table shows results using the 'log-PME' estimation. Abnormal performance (Alpha) and risk loadings using either a one factor market model (S\&P 500; specs 1, 3 and 5) or the three-factor FamaFrench model (specs 2, 4 and 6). Standard errors (obtained by bootstrapping) are below between parenthesis. Panel A shows results for Venture Capital funds and Panel B shows results for Buyout funds. Below each specification, the autocorrelation of the pricing errors computed over the 14 moment conditions is reported with their corresponding standard errors. At the bottom of the table, Alpha and Beta_Market are evaluated at the first size-quartile (small) and third size-quartile (large). Monthly alpha is shown in spec 1 and spec 2 . In specs 3 and 5 , the underlying models are respectively: R-Rf $=$ $\mathrm{a}_{0}+\mathrm{a}_{\text {size }} * \ln ($ Size $)+$ Beta_market* $*(\mathrm{Rm}-\mathrm{Rf})+\mathrm{e}$ and $\mathrm{R}-\mathrm{Rf}=\mathrm{a}_{0}+\mathrm{a}_{\text {size }} * \ln (\operatorname{Size})+\left(\mathrm{b}_{0}+\mathrm{b}_{\text {size }} * \ln (\operatorname{Size})\right) *(\mathrm{Rm}-$ Rf) + e. Specs 4 and 6 are like specs 3 and 5 with the two Fama-French additional factors.

Panel A: Venture Capital Funds

\begin{tabular}{|c|c|c|c|c|c|c|}
\hline & Spec 1 & Spec 2 & Spec 3 & Spec 4 & Spec 5 & Spec 6 \\
\hline Alpha (\%, monthly) & $\begin{array}{r}* * *-1.25 \\
(0.05)\end{array}$ & $\begin{array}{r}-0.69 \\
(0.38)\end{array}$ & & & & \\
\hline $\mathrm{a}_{0}$ & & & $\begin{array}{r}* * *-2.14 \\
(0.22)\end{array}$ & $\begin{array}{r}* *-2.08 \\
(0.36)\end{array}$ & $\begin{array}{r}{ }^{* *}-1.61 \\
(0.42)\end{array}$ & $\begin{array}{r}-1.05 \\
(0.78)\end{array}$ \\
\hline$a_{\text {size }}$ & & & $\begin{array}{r}{ }^{* * *} 0.18 \\
(0.05)\end{array}$ & $\begin{array}{r}{ }^{* * *} 0.18 \\
(0.05)\end{array}$ & $\begin{array}{r}0.08 \\
(0.09)\end{array}$ & $\begin{array}{r}0.02 \\
(0.14)\end{array}$ \\
\hline Beta_Market & $\begin{array}{r}* * * 3.21 \\
(0.22)\end{array}$ & $\begin{array}{r}* * * 2.57 \\
(0.49)\end{array}$ & $\begin{array}{l}{ }^{* * * *} 2.70 \\
(0.32)\end{array}$ & $\begin{array}{l}* * * * 2.85 \\
(0.52)\end{array}$ & & \\
\hline $\mathrm{b}_{0}$ & & & & & $\begin{array}{r}0.15 \\
(1.50)\end{array}$ & $\begin{array}{r}-0.62 \\
(2.03)\end{array}$ \\
\hline$b_{\text {size }}$ & & & & & $\begin{array}{r}{ }^{*} 0.57 \\
(0.34)\end{array}$ & $\begin{array}{r}0.67 \\
(0.44)\end{array}$ \\
\hline Beta_SMB & & $\begin{array}{r}0.99 \\
(0.78)\end{array}$ & & $\begin{array}{r}-0.26 \\
(0.55)\end{array}$ & & $\begin{array}{r}0.46 \\
(0.53)\end{array}$ \\
\hline Beta_HML & & $\begin{array}{r}-0.56 \\
(0.42)\end{array}$ & & $\begin{array}{r}-0.29 \\
(0.33)\end{array}$ & & $\begin{array}{r}-0.17 \\
(0.34)\end{array}$ \\
\hline Number obs. & 686 & 686 & 686 & 686 & 686 & 686 \\
\hline Error autocorrelation & $\begin{array}{r}-0.16 \\
(0.26)\end{array}$ & $\begin{array}{r}-0.28 \\
(0.26)\end{array}$ & $\begin{array}{c}-0.31 \\
(0.25)\end{array}$ & $\begin{array}{c}-0.21 \\
(0.25)\end{array}$ & $\begin{array}{r}-0.26 \\
(0.23)\end{array}$ & $\begin{array}{r}-0.27 \\
(0.24)\end{array}$ \\
\hline Alpha - Small funds & - & - & -1.53 & -1.48 & -1.34 & -1.00 \\
\hline Alpha - Large funds & - & - & -1.30 & -1.25 & -1.24 & -0.98 \\
\hline Beta - Small funds & - & _- & - & - & 2.04 & 1.60 \\
\hline Beta - Large funds & _ & _- & _ & _- & 2.74 & 2.43 \\
\hline
\end{tabular}


Panel B: Buyout Funds

\begin{tabular}{|c|c|c|c|c|c|c|}
\hline & Spec 1 & Spec 2 & Spec 3 & Spec 4 & Spec 5 & Spec 6 \\
\hline Alpha (\%, monthly) & $\begin{array}{r}0.49 \\
(0.37)\end{array}$ & $\begin{array}{r}0.13 \\
(0.44)\end{array}$ & & & & \\
\hline $\mathrm{a}_{0}$ & & & $\begin{array}{r}-0.08 \\
(0.55)\end{array}$ & $\begin{array}{r}-0.35 \\
(0.77)\end{array}$ & $\begin{array}{r}{ }^{* * *} 2.63 \\
(0.80)\end{array}$ & $\begin{array}{r}2.21 \\
(1.41)\end{array}$ \\
\hline$a_{\text {size }}$ & & & $\begin{array}{r}0.07 \\
(0.08)\end{array}$ & $\begin{array}{r}0.08 \\
(0.07)\end{array}$ & $\begin{array}{r}{ }^{* * *}-0.39 \\
(0.13)\end{array}$ & $\begin{array}{r}-0.35 \\
(0.23)\end{array}$ \\
\hline Beta_Market & $\begin{array}{r}0.33 \\
(0.38)\end{array}$ & $\begin{array}{r}{ }^{* *} 0.94 \\
(0.44)\end{array}$ & $\begin{array}{r}0.23 \\
(0.05)\end{array}$ & $\begin{array}{r}0.57 \\
(0.54)\end{array}$ & & \\
\hline $\mathrm{b}_{0}$ & & & & & $\begin{array}{r}* * *-3.37 \\
(0.68)\end{array}$ & $\begin{array}{l}{ }^{*}-3.16 \\
(1.60)\end{array}$ \\
\hline $\mathrm{b}_{\text {size }}$ & & & & & $\begin{array}{r}{ }^{* * *} 0.64 \\
(0.12)\end{array}$ & $\begin{array}{r}{ }^{* *} 0.64 \\
(0.28)\end{array}$ \\
\hline Beta_SMB & & $\begin{array}{r}* * *-2.05 \\
(0.79)\end{array}$ & & $\begin{array}{r}{ }^{* * *}-1.78 \\
(0.64)\end{array}$ & & $\begin{array}{r}{ }^{* * *}-1.58 \\
(0.58)\end{array}$ \\
\hline Beta_HML & & $\begin{array}{r}-0.16 \\
(0.86)\end{array}$ & & $\begin{array}{r}0.13 \\
(1.13)\end{array}$ & & $\begin{array}{r}0.34 \\
(1.00)\end{array}$ \\
\hline Number obs. & 686 & 686 & 686 & 686 & 686 & 686 \\
\hline Error autocorrelation & $\begin{array}{r}0.35 \\
(0.30)\end{array}$ & $\begin{array}{r}-0.08 \\
(0.35)\end{array}$ & $\begin{array}{r}0.18 \\
(0.36)\end{array}$ & $\begin{array}{r}-0.18 \\
(0.35)\end{array}$ & $\begin{array}{r}0.19 \\
(0.35)\end{array}$ & $\begin{array}{r}-0.11 \\
(0.35)\end{array}$ \\
\hline Alpha - Small funds & - & - & 0.22 & -0.03 & 1.02 & 0.77 \\
\hline Alpha - Large funds & - & - & 0.36 & 0.11 & 0.32 & 0.15 \\
\hline Beta - Small funds & - & - & - & - & -0.74 & -0.54 \\
\hline Beta - Large funds & _ & _ & _ & _ & 0.42 & 0.60 \\
\hline
\end{tabular}


Table 5: Impact of final NAV treatment on risk and abnormal return

This table is like Table 4. Instead of jointly estimating the final Net Asset Value (NAV) and the risk profile, it treats final NAVs either as market value or as worthless (written off). Betas and monthly alphas are shown with standard errors underneath.

\begin{tabular}{|c|c|c|c|c|c|c|c|c|}
\hline & \multicolumn{4}{|c|}{ Final NAV as market value } & \multicolumn{4}{|c|}{ Final NAV written off } \\
\hline & \multicolumn{2}{|c|}{ Venture Capital } & \multicolumn{2}{|c|}{ Buyout } & \multicolumn{2}{|c|}{ Venture Capital } & \multicolumn{2}{|c|}{ Buyout } \\
\hline & Spec 1 & Spec 2 & Spec 1 & Spec 2 & Spec 1 & Spec 2 & Spec 1 & Spec 2 \\
\hline \multirow[t]{2}{*}{ Alpha (\%) } & ${ }^{* * * *}-1.08$ & ${ }^{* *}-0.60$ & 0.37 & 0.19 & ${ }^{* * * *}-1.27$ & -0.51 & ${ }^{*} 0.62$ & 0.13 \\
\hline & $(0.06)$ & $(0.26)$ & (0.33) & (0.38) & $(0.06)$ & $(0.42)$ & $(0.36)$ & $(0.62)$ \\
\hline \multirow[t]{2}{*}{ Beta } & ${ }^{* * *} 3.45$ & ${ }^{* * *} 2.58$ & 0.59 & ${ }^{* *} 1.06$ & ${ }^{* * *} 2.98$ & ${ }^{* * *} 2.27$ & 0.14 & 0.75 \\
\hline & $(0.17)$ & $(0.29)$ & (0.39) & $(0.43)$ & $(0.28)$ & $(0.45)$ & $(0.35)$ & $(0.50)$ \\
\hline \multirow[t]{2}{*}{ SMB } & & ${ }^{* *} 1.35$ & & $* *-1.57$ & & ${ }^{*} 1.32$ & & ** -2.56 \\
\hline & & $(0.40)$ & & $(0.71)$ & & $(0.78)$ & & (1.06) \\
\hline \multirow[t]{2}{*}{ HML } & & -0.34 & & -0.08 & & -0.64 & & 0.40 \\
\hline & & (0.37) & & $(0.66)$ & & $(0.45)$ & & $(1.20)$ \\
\hline
\end{tabular}




\section{Table 6: Robustness Tests}

This table is like Table 4. It shows the alpha and beta for a CAPM specification for different empirical design. Moment conditions are either weighted by the number of funds of each fund-of-funds (N_funds weighted) or by the total size of each fund-of-funds (Value weighted). Parameter estimates are shown for different number of fund-of-funds (FoFs), method (PME instead of log-PME), time periods, subsample (US-focused), and benchmarks. Benchmarks include Nasdaq, and Ken French value-weighted indices (Small growth 5x5, Europe dollar return, United Kingdom dollar return).

\begin{tabular}{|c|c|c|c|c|c|c|c|c|}
\hline & \multicolumn{4}{|c|}{ (N_funds) Weighted Moments } & \multicolumn{4}{|c|}{ Value Weighted Moments } \\
\hline & \multicolumn{2}{|c|}{ VC } & \multicolumn{2}{|c|}{$\mathrm{BO}$} & \multicolumn{2}{|c|}{ VC } & \multicolumn{2}{|c|}{ BO } \\
\hline & Alpha & Beta & Alpha & Beta & Alpha & Beta & Alpha & Beta \\
\hline Default (Table 4) & -1.24 & 3.21 & 0.49 & 0.33 & -1.22 & 3.13 & 0.06 & 0.75 \\
\hline \multicolumn{9}{|l|}{ Number FoFs per vint. year } \\
\hline Default + 1 (2 FoFs) & -1.38 & 2.88 & 0.25 & 0.31 & -1.24 & 3.12 & -0.02 & 0.82 \\
\hline Default + 2 (3 FoFs) & -1.40 & 2.76 & 0.11 & 0.28 & -1.23 & 3.18 & 0.03 & 0.73 \\
\hline Default + 3 (4 FoFs) & -1.38 & 2.65 & -0.10 & 0.57 & -1.23 & 3.17 & -0.02 & 0.80 \\
\hline PME method & -1.20 & 3.19 & 0.97 & -0.02 & -1.15 & 3.04 & 0.46 & 0.41 \\
\hline \multicolumn{9}{|l|}{ Vintage cut (default is 1993) } \\
\hline Default + 1 (1980-1994) & -1.24 & 3.22 & 0.63 & 0.16 & -1.21 & 3.14 & 0.17 & 0.57 \\
\hline Default - 1 (1980-1992) & -1.26 & 3.15 & 0.47 & 0.38 & -1.23 & 3.07 & 0.00 & 0.83 \\
\hline US focus only & -1.10 & 3.55 & 0.83 & 0.11 & -1.11 & 3.50 & 0.37 & 0.50 \\
\hline \multicolumn{9}{|l|}{ Other benchmarks } \\
\hline S\&P500 and \$-EU index & -0.94 & 3.76 & 0.59 & 0.34 & -0.92 & 3.82 & 0.46 & 0.44 \\
\hline S\&P500 and \$-UK index & -1.10 & 3.57 & 0.40 & 0.47 & -1.09 & 3.61 & -0.02 & 0.87 \\
\hline Nasdaq & -0.52 & 1.55 & & & -0.47 & 1.47 & & \\
\hline Small Growth & 1.47 & 1.70 & & & 1.43 & 1.65 & & \\
\hline
\end{tabular}


Figure 1: GMM goal function as a function of alpha and beta for the NPV method in a simulated economy.

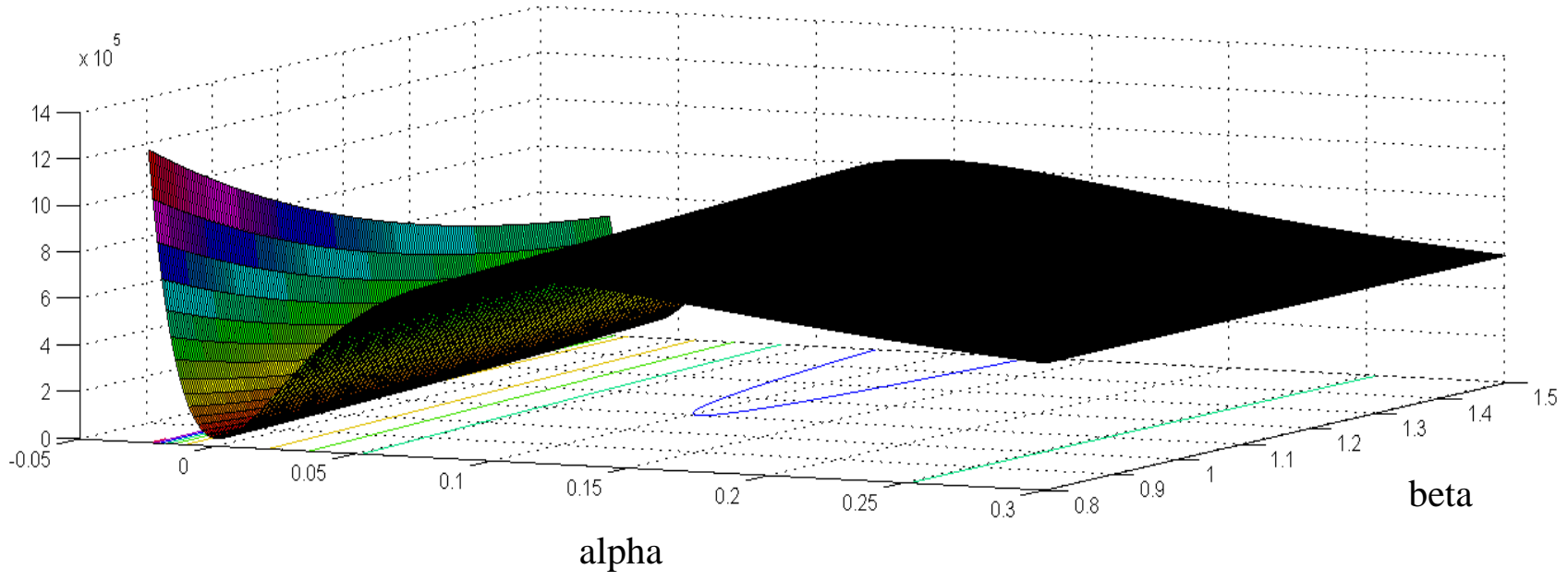

Figure 2: GMM goal function as a function of alpha and beta for the log-PME method in a simulated economy.

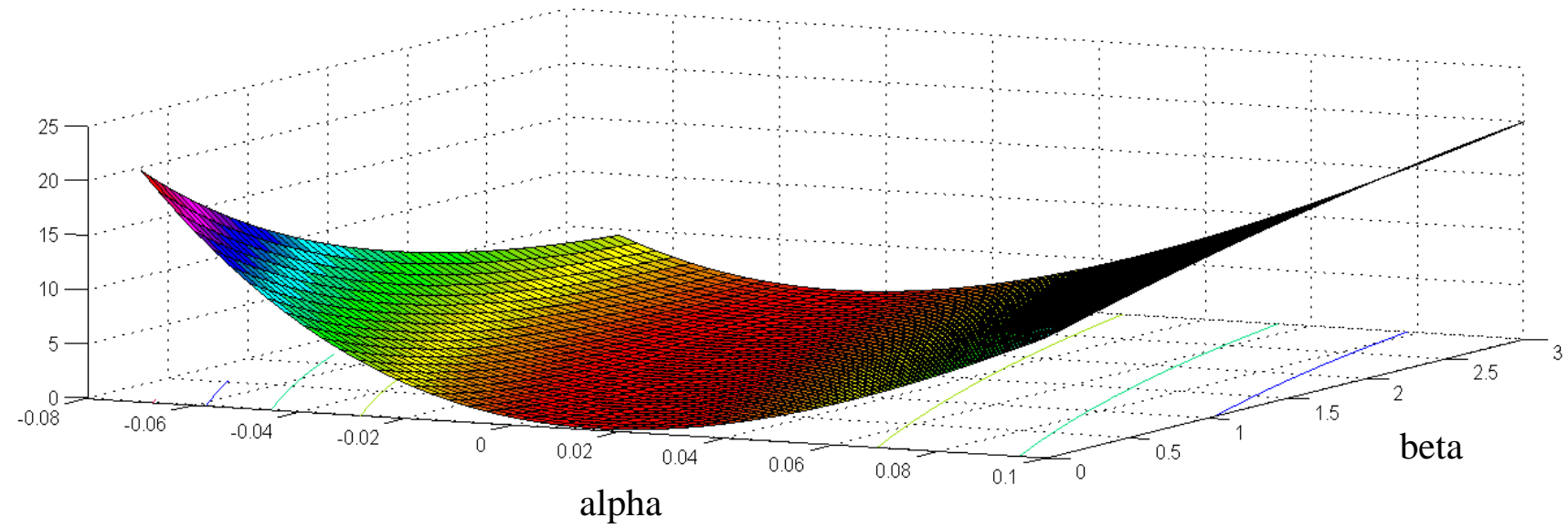


Figure 3: Fund dividend yields (average of the next 12 months dividend yields of funds in their $4^{\text {th }}$ to $10^{\text {th }}$ year). Dividend yield is the sum of the dividends paid divided by fund size. S\&P 500 returns are the 5 years cumulated returns, divided by 5. Time spans 1990 to 2003 .

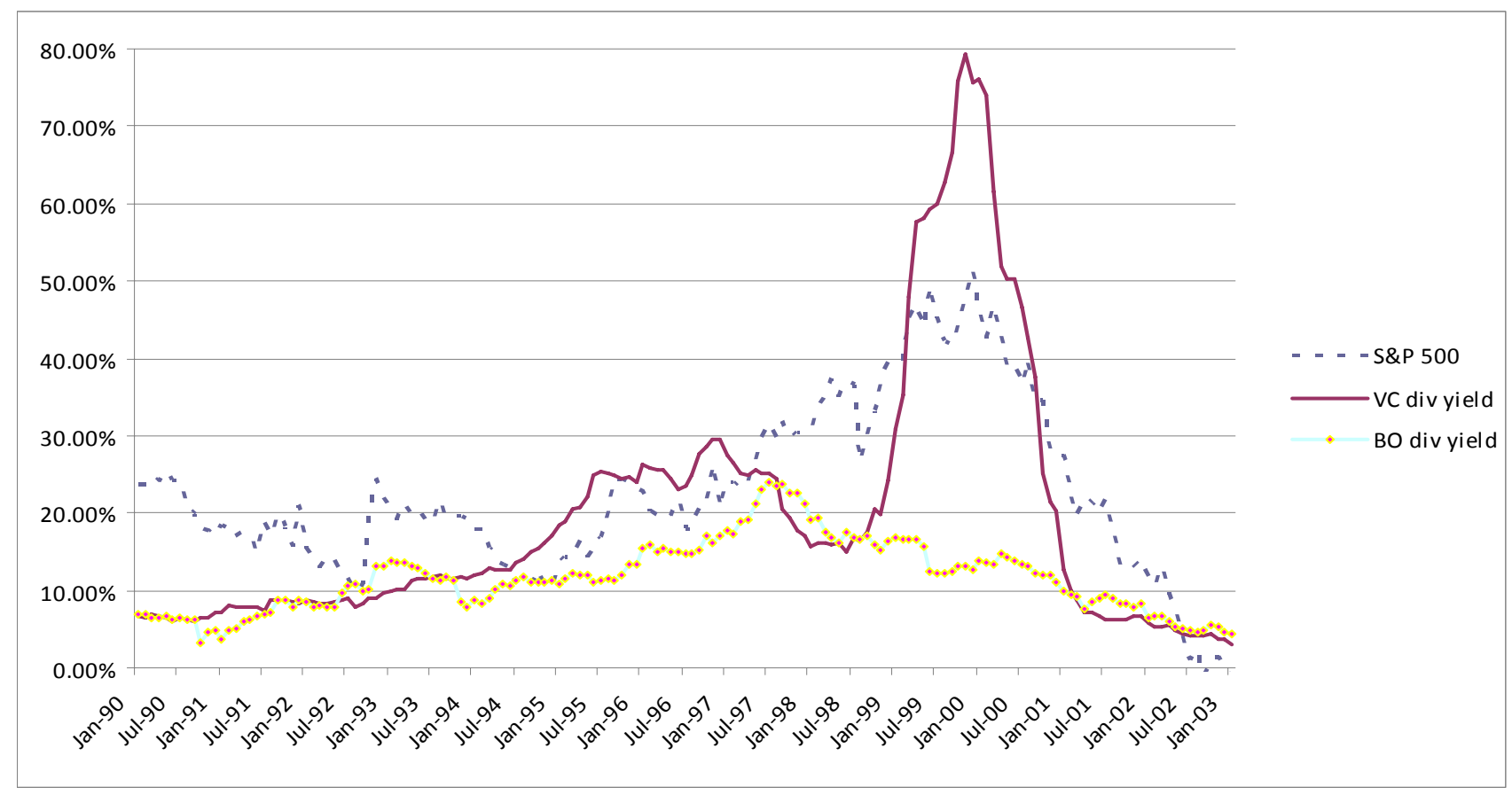

